\title{
Myocyte Enhancer Factor 2c Regulates Dendritic Complexity and Connectivity of Cerebellar Purkinje Cells
}

\author{
Sandhya Prakash Kamath ${ }^{1} \cdot$ Albert I. Chen ${ }^{1,2,3}$ [D \\ Received: 27 April 2018 / Accepted: 21 September 2018 / Published online: 1 October 2018 \\ (C) The Author(s) 2018
}

\begin{abstract}
Mef2c haploinsufficiency is implicated in behavioral deficits related to autism, schizophrenia, and intellectual disability. Although perturbations in the cerebellum, notably Purkinje cells, have been linked to these neurological disorders, the underlying mechanisms remain poorly understood. In this study, we investigated the roles of Mef2c in cerebellar Purkinje cells during the first three weeks of postnatal development. Our analysis revealed that in comparison to other members of the Mef family, Mef2c expression is limited to postnatal Purkinje cells. Because the role of Mef2c has not been assessed in GABAergic neurons, we set out to determine the functional significance of Mef2c by knocking down the expression of Mef2c selectively in Purkinje cells. We found that the loss of Mef2c expression during the first and second postnatal week results in an increase in dendritic arborization without impact on the general growth and migration of Purkinje cells. The influence of Mef2c on dendritic arborization persists throughout the first three weeks, but is most prominent during the first postnatal week suggesting a critical period of Mef2c activity. Additionally, the loss of Mef2c expression results in an increase in the number of spines accompanied by an increase in Gad67 and vGluT1 puncta and decrease in vGluT2 puncta. Thus, our results reveal the specific expression and functional relevance of Mef2c in developing Purkinje cells and offer insight to how disruption of the expression of Mef2c in a GABAergic neuronal subtype may lead to pathogenesis of cerebellar-associated disorders.
\end{abstract}

Keywords Mef2c $\cdot$ Cerebellum $\cdot$ Purkinje cells $\cdot$ GABAergic neurons $\cdot$ Dendrites $\cdot$ Spines

\section{Introduction}

The transcription factor myocyte enhancer factor $2 \mathrm{c}$ (Mef2c) has been identified in human genetic analysis as a susceptibility gene for a number of neurological disorders. The partial loss of Mef2c, referred to as Mef2c haploinsufficiency syndrome, has been linked to autism spectrum disorder (ASD), schizophrenia, and intellectual disability, which are thought to be caused by impairments

Electronic supplementary material The online version of this article (https://doi.org/10.1007/s12035-018-1363-7) contains supplementary material, which is available to authorized users.

Albert I. Chen

albert.chen@ntu.edu.sg

1 School of Biological Sciences, Nanyang Technological University (NTU), Singapore 637551, Singapore

2 A*STAR, Institute of Molecular and Cell Biology, Singapore 138673, Singapore

3 School of Life Sciences, University of Warwick, Coventry CV4 7AL, UK during early stages of neural development [1-3]. In addition to regulation of the development of muscle, bone, and lymphocytes [4], Mef2c orchestrates neuronal differentiation and survival as well as synapse formation in rodents [5-12]. Mef2c is expressed in many parts of the human and rodent brain [13-15], and activation of the transcriptional activity of Mef2 family members by neurotrophin and calcium influx controls a number of excitatory synapses $[6,16]$. Despite the emerging role of $\mathrm{Mef} 2 \mathrm{c}$ as an important activity-dependent regulator of neural processes, details of its expression pattern and function have only been assessed in select regions of the brain. Mouse genetic studies have identified key roles of Mef2 in neurons of the cerebral cortex and hippocampus [5, 9-12], but consequences of deletion of Mef2 genes on the development of the cerebellum have not yet been examined or reported. Moreover, the role of Mef2c in GABAergic neurons is unknown.

There is growing support for the link between dysfunction of the cerebellum and neurological disorders such as ASD [17-19], and both human and animal studies point to a reduction in the number or disrupted function of 
Purkinje cells [20-23]. Purkinje cells are GABAergic projection neurons located in the cerebellar cortex that receive inhibitory input from molecular layer interneurons and excitatory input from parallel and climbing fibers [24, 25]. Generation of Purkinje cells in mice begins at embryonic day 10.5 when they begin to proliferate, migrate, and differentiate until birth [26, 27]. Dendritic formation and spinogenesis, on the other hand, involve the addition and retraction of processes that occur during the first 3 weeks of postnatal development [28]. Purkinje cell dendrites develop from multiple perisomatic processes to a single apical stem during the first postnatal week, and the rapid branching of the apical stem dendritic tree takes place during the second week [28]. Disruptions in one or more of these events during development could perturb the function of Purkinje cells leading to an imbalance of excitation and inhibition, which is often associated with neurological disorders [29, 30]. Thus, the identification and characterization of factors that coordinate complex processes such as dendritic outgrowth and synaptic organization in Purkinje cells may provide insight into how perturbations in cerebellar circuits could lead to disorders associated with the cerebellum.

In this study, we characterize the spatio-temporal expression pattern of Mef2c in the mouse cerebellum and show that Mef2c is specifically expressed in Purkinje cells in the postnatal cerebellar cortex. Since the onset of Mef2c expression coincides with a period of rapid structural changes in Purkinje cell dendrites, we explored its role in dendritic morphogenesis and synapse formation. Using a Purkinje cell-specific promoter to drive shRNA targeted against Mef2c and selectively label individual Purkinje cells, we analyzed consequences of Mef2c knockdown during early postnatal development. We found that the loss of Mef2c expression results in an increase in dendritic complexity, and the influence of Mef2c persists throughout the first 3 weeks. Our results indicate that the first postnatal week may be a critical period of Mef2c activity because the loss of Mef2c expression during this period results in a more pronounced change in properties of Purkinje cell dendrites. We also observe that reducing the expression of Mef2c results in a modest increase in the number of distal spines, but not the length of spines. The loss of Mef2c also leads to changes in localization of vGluT1 and vGluT2 puncta on Purkinje cell dendrites, indicating disrupted input from climbing and parallel fibers. Additionally, loss of Mef2c results in an increase in Gad67 puncta on Purkinje cell dendrites and soma. Taken together, we show that the expression of Mef2c in Purkinje cells is a determinant of dendritic complexity and synaptic input and provide evidence that the perturbation of a key transcription factor linked to neurological disorders in GABAergic neurons may underlie pathogenesis of cerebellar-associated disorders.

\section{Materials and Methods}

\section{Animals and Ethics Statement}

All experiments conducted were approved by the Institutional Animal Care and Use Committee in accordance with the guidelines stated by the National Advisory Committee for Laboratory Animal Research. C57BL/6N mice were housed in the Biological Research Center under the management of the Agency for Science, Technology and Research and Animal Research Facility, LKC School of Medicine, Nanyang Technological University, Singapore. Mice were provided ad libitum access to food and water and were reared on a 12-h light-dark cycle.

\section{Histology}

For in situ hybridization, mice were euthanized using a $\mathrm{CO}_{2}$ chamber, the brains were extracted and incubated overnight in $4 \%$ paraformaldehyde (Sigma). On the subsequent day, fixed brains were transferred into $30 \%$ sucrose solution (1st base) and dehydrated overnight, following which they were mounted in optimal cutting temperature (Sakura Finetek) compound and frozen using dry ice. For immunohistochemistry, mice were anesthetized by intraperitoneal injection of $2.5 \%$ Avertin $[0.025 \mathrm{~g} / \mathrm{mL}$ of 2,2,2-tribromoethanol (Sigma), mixed with 2-methyl-2-butanol, (Sigma)]. Once they were completely sedated, cardiac perfusion was carried out first with $0.9 \%$ saline, followed by $4 \%$ paraformaldehyde. The brains were then transferred to $30 \%$ sucrose and allowed to dehydrate overnight. Once they were sunken in the sucrose bed, they were either flash frozen in optimal cutting temperature compound or used directly for vibratome sectioning.

Brains used for in situ hybridization analysis and characterization of Mef2c expression were sectioned on a cryostat in $20-\mu \mathrm{m}$ thickness. Sections were collected on Superfrost plus microscopic slides (Thermo Fisher) and were allowed to dry in room temperature for $20 \mathrm{~min}$. Sections were either used immediately or stored in $-80^{\circ} \mathrm{C}$. Tissues used for the morphological analysis of Purkinje cells were $100 \mu \mathrm{m}$ thick and sectioned using a vibratome (Leica VT 1000 S), which were then used directly for immunohistochemical analysis or stored in tissue collection solution (TCS) [25\% glycerin, 30\% ethylene glycol, $1.38 \mathrm{~g} / \mathrm{L}$ monosodium phosphate, and $5.48 \mathrm{~g} / \mathrm{L}$ disodium phosphate (Sigma)] at $-20{ }^{\circ} \mathrm{C}$ until further use.

\section{In Situ Hybridization}

RNA probes with approximate lengths of 900 bps were generated for all four members of the Mef2 family using the following sequences: Mef2a: 5'-CAGCCAGCTCAACA TTAGCA-3', Mef2b: 5'-GTGCTTTGTGACTGCGACAT-3', Mef2c: 5'-TGATCAGCAGGCAAAGATTG-3', Mef2d: 5'- 
CACTCCTTCCCTGGTGACAT-3'. The T7 polymerase sequence 5'-GCGCTAATACGACTCACTATAGGG-3' was added to the $5^{\prime}$ end of the reverse primer. Total cerebellar RNA of mouse origin (Clontech) was reversed transcribed (Thermo Scientific) to generate template cDNA. Polymerase chain reaction (i-DNA Technology) was carried out with the primers and the resulting product was labeled with 11digoxygenin-UTP (Roche). Chromogenic in situ hybridization was then carried out as previously described [31].

\section{Lentivirus Production and Intracranial Injection into Neonatal Mice}

Viral particles with titers $>10^{8} \mathrm{TU} / \mathrm{mL}$ were commercially produced by Vector Builder (Cyagen Biosciences) according to the construct designs provided. The L7 plasmid was a gift from Dr. Hirokazu Hirai, Gunma University, Japan [32]. The nucleotide sequences for shRNAs used are as follows: scrambled: 5'-CCCTAAGGTTAAGTCGCCCTCG-3' and Mef2c: 5'-GGAACAACTTCCTGGAGAAGC-3'.

Intracranial injection of lentiviruses was carried out on 1-, 3-, and 7-day-old pups as described in [33] with some differences. The pups were separated from their mothers and anesthetized on ice until immobilized. This process is done one pup at a time to avoid the basal body temperatures from dropping drastically. L7-shRNA-IRES-GFP lentivirus is first diluted to $10^{6}$ by mixing with $2.5 \mathrm{mg} / \mathrm{mL}$ Fast Green FCF dye (Sigma), which was used to visualize the site and spread of the virus injected. An anesthetized pup was then placed on an ice pack and its head was wiped down with a cotton swab soaked in $70 \%$ ethanol. One microliter of virus was introduced into each injection site along the late maturing lobules of the cerebellum. Bilateral injections were carried out on lobules IVVIII with one injection on each lobule. As the skin of young mice pups was translucent, the lambda suture point was visible and served as a landmark for the injection along the mediolateral and rostro-caudal axis of the cerebellum. The needle was inserted perpendicular to the skull at a depth of $500 \mu \mathrm{m}$ which was then held in place for 3 min to prevent backflow. Since injections were carried out in the same litter, sterile tattoo ink was injected into the palms to distinguish the control from the experimental pups. Subsequently, all the injected pups were placed on a heating pad until they recover and were returned to their home cage where they were held until a specific experimental time point.

\section{Immunohistochemistry}

Primary antibodies and dilutions used in this study: rabbit anti-Mef2c (1:500, Cell Signaling), mouse anti-mGluR2 (1:1500, Advanced Targeting Systems), mouse anti-NeuN (1:1000, Millipore), mouse anti-Calbindin (1:5000, Swant), goat anti-parvalbumin $(1: 2500$, Swant), rat anti-GFP
(1:1000, Nacalai Tesque), guinea pig anti-vGluT2 (1:2000, Millipore), rabbit anti-GFAP (1:500, Sigma Aldrich), and guinea pig anti-zebrin (1:1000, Frontier Institute). All secondary antibodies used were obtained from molecular probes and diluted 1:1000 prior to use.

\section{For 20- $\mu \mathrm{m}$ Sections}

Tissues were first permeabilized for 10 min with $0.2 \%$ Triton$\mathrm{X}$ (OmniPur) diluted in phosphate buffered saline (PBS) (first base). The slides were then blocked with $3 \%$ horse serum (Invitrogen) in $0.1 \%$ Triton-X (OmniPur) in PBS. Primary antibodies were diluted in blocking buffer and added onto the slides before incubating them overnight at $4{ }^{\circ} \mathrm{C}$. The following day, corresponding secondary antibodies were diluted 1:1000 each and incubated for $2 \mathrm{~h}$ at room temperature. Freshly prepared $0.1 \mu \mathrm{g} / \mathrm{mL}$ DAPI (Sigma) was prepared and the slides were incubated for $10 \mathrm{~min}$ and mounted with Prolong Gold (molecular probes). The mounting agent was allowed to set overnight away from light before subsequent confocal imaging.

\section{For $100-\mu \mathrm{m}$ Sections}

Free-floating immunohistochemistry was carried out for $100-\mu \mathrm{m}$ sections. Brain tissues sectioned using the vibratome were either stored in TCS solution as mentioned previously or immediately processed. The tissue sections were first washed with PBS (First Base) and subsequently permeabilized using $0.3 \%$ Triton- $\mathrm{X}$ for $1 \mathrm{~h}$ at room temperature. The tissue sections were then incubated for another hour in blocking solution composed of $3 \%$ horse serum and $0.1 \%$ Triton-X. Sections were stained for two nights in specific concentrations of the respective antibodies. Subsequently, tissues were stained with secondary antibodies Alexa fluor 488/555/647 and $0.1 \mu \mathrm{g} / \mathrm{mL}$ DAPI and mounted using Prolong Gold.

\section{Image Analysis and Quantification}

All images in this report were captured using $\times 10, \times 20$, or $\times$ 63 oil objective on the Zeiss LSM-710 Confocal Microscope System (Axio Imager Z2). Images obtained were in an 8-bit format and imaging parameters such as laser power, digital gain, and offset were kept unchanged for each experiment. Processing was carried out using ImageJ and Fiji.

\section{Intensity Measurement}

In order to quantify the expression level of Mef2c in $\mathrm{GFP}^{+}$ Purkinje cells, z-stack images of $10 \mu \mathrm{m}$ were acquired using a $\times 20$ objective. Images were acquired in steps of $1 \mu \mathrm{m}$ and compressed before analysis. The threshold for each of these channels was then independently determined as mentioned 
previously [34], but with slight modifications. The average pixel intensity of at least five non-overlapping regions was first calculated and the standard deviation generated was added to this value. Using the subtract function in ImageJ, background was eliminated from the image. Similar to the method used for cell counting, the elliptical tool was selected and each individual Purkinje cell was drawn and the intensity was determined for the respective channels. These intensities were then further normalized to account for the disparity in antibody staining from one experiment to the next. Average intensity values were obtained for both the control and experimental Purkinje cells from at least five images taken from two to three different slides. The number obtained from dividing average intensity of the experimental group versus the control group was used to normalize all the images.

\section{vGluT1/2 and Gad67 Puncta Quantification}

To analyze vGluT2 puncta on PC dendrites, z-stack images of $10-\mu \mathrm{m}$ thickness, in steps of 0.5 , were obtained using a $\times 63$ oil objective. ImageJ was used to convert these images into maximum intensity stacks, after which threshold adjustment was carried out as mentioned above to obtain the final images. The GFP channel was converted to green and vGluT2 was converted to red. Using the RG2B plugin on ImageJ, which supports only dual-channel colocalization, yellow puncta were identified within manually drawn regions of interest, either covering the full area of the soma or the dendrites. Analyze Particle property on ImageJ was then applied to determine the ratio of the area of vGluT2 puncta in the specified dendritic region. Normalization was carried out in the same way mentioned above, but with the average number of particles in the control and experimental groups, instead of pixel intensity. All further statistical tests were carried out using GraphPad Prism.

\section{Dendrite Tracing and Analysis}

For morphological analysis of Purkinje cells at P14 and P21, $\times 20$ stack images in 50- and 80- $\mu$ m (steps of 1 ) thickness were obtained, respectively. Following the aforementioned method of threshold adjustment, each dendritic tree of Purkinje cells was traced out manually using Simple Neurite Tracer plugin on Fiji [35]. 3D-Sholl analysis using concentric circles in steps of $10 \mu \mathrm{m}$ was conducted using the plugin on ImageJ to obtain data for maximum intersections, radii of maximum intersections, and intersection number vs distance from soma, all analyzed on GraphPad.

\section{Spine Analysis}

A $\times 63$ oil immersion objective was used to take $20-\mu \mathrm{m}$ stack images. Maximum intensity projections of this stack, taken in steps of 0.5 , were generated and threshold values were calculated as previously described [34]. Images were then converted to grayscale and spines were manually counted from at least 20 independent tertiary/terminal dendrites using the Cell Counter function on ImageJ. The total number of spines was determined in 10- $\mu \mathrm{m}$ stretches of dendrite per neuron and density was calculated as the number of spines divided by 10 . Lengths of individual spines were measured as the distance from the mid-line of each spine to the tip of the spine head. GraphPad was employed for subsequent $t$ test analysis.

\section{Statistical Analysis}

All data obtained was analyzed using GraphPad Prism. The pattern of data distribution and outliers was first identified for each data set using the respective tools on GraphPad. Numbers including animals used, puncta, dendrites, spines, and cells counted are stated in each figure legend. For this study, only apical Purkinje cells from lobules III-VIII of the vermis region were used for analysis. Unpaired $t$ tests were used for all the experiments.

\section{Results}

\section{The Expression of Mef2c RNA and Protein Is Restricted to Purkinje Cells in the Postnatal Cerebellar Cortex}

Analysis of the expression of Mef2 family of transcription factors in the human and mouse brain has revealed that all four Mef2 genes are expressed in the cerebellar cortex [36], but details of the temporal and spatial expression pattern within specific neuronal subtypes are not clear. To characterize the expression of Mef2 genes in the cerebellar cortex, we generated RNA probes specific for each homolog and performed chromogenic in situ hybridization analysis in lobule VIII of cerebellar sections obtained from postnatal day (P) 60 mice. The expression of Mef2a and Mef2d is found in the molecular layer and Purkinje cell layer, indicating that these two Mef2 family members are expressed by stellate/basket cells and Purkinje cells (Fig. 1 b, e). The widespread expression throughout the internal granular layer indicates that granule cells express both Mef2a and Mef2d, and the sparsely distributed intense expression suggests that they may also be expressed by Golgi cells (white arrows, Fig. 1 b, e). Mef $2 b$ expression, on the other hand, is not detected in the cerebellar cortex (Fig. 1c). Mef2c expression is restricted to the Purkinje cell layer, and not detected in the molecular or internal granular layer (Fig. 1d). Comparison with Gad67, a gene expressed by cerebellar GABAergic inhibitory neurons [37], shows that unlike Mef2a or Mef $2 d$ which are expressed in all three layers of the cerebellar cortex, Mef2c expression 
Fig. 1 Distinct expression of Mef 2 genes in the cerebellar cortex. a Schematic diagram of a sagittal section of the cerebellum with red box indicating lobule VIII where subsequent images are derived from. b Mef $2 a$ expression is observed in the ML, PL and IGL layers of the cerebellar cortex (white arrows indicate

presumptive Golgi cells). c Mef $2 b$ expression is not detected in any of the cerebellar cortical layers. $\mathbf{d}$ $M e f 2 c$ expression is limited to the $\mathrm{PL}$ indicating specific expression in Purkinje cells. e Mef2d expression is found in the ML, PL and IGL layers (white arrows indicate presumptive Golgi cells). f $\operatorname{Gad} 67$, a marker for

GABAergic neurons, is observed in stellate and basket cells in the ML, Purkinje cells in the PL and Golgi cells in the IGL. PL, Purkinje cell layer; ML, molecular layer; IGL, internal granule layer. Age $=$ P60. Scale bar $=20 \mu \mathrm{m}$
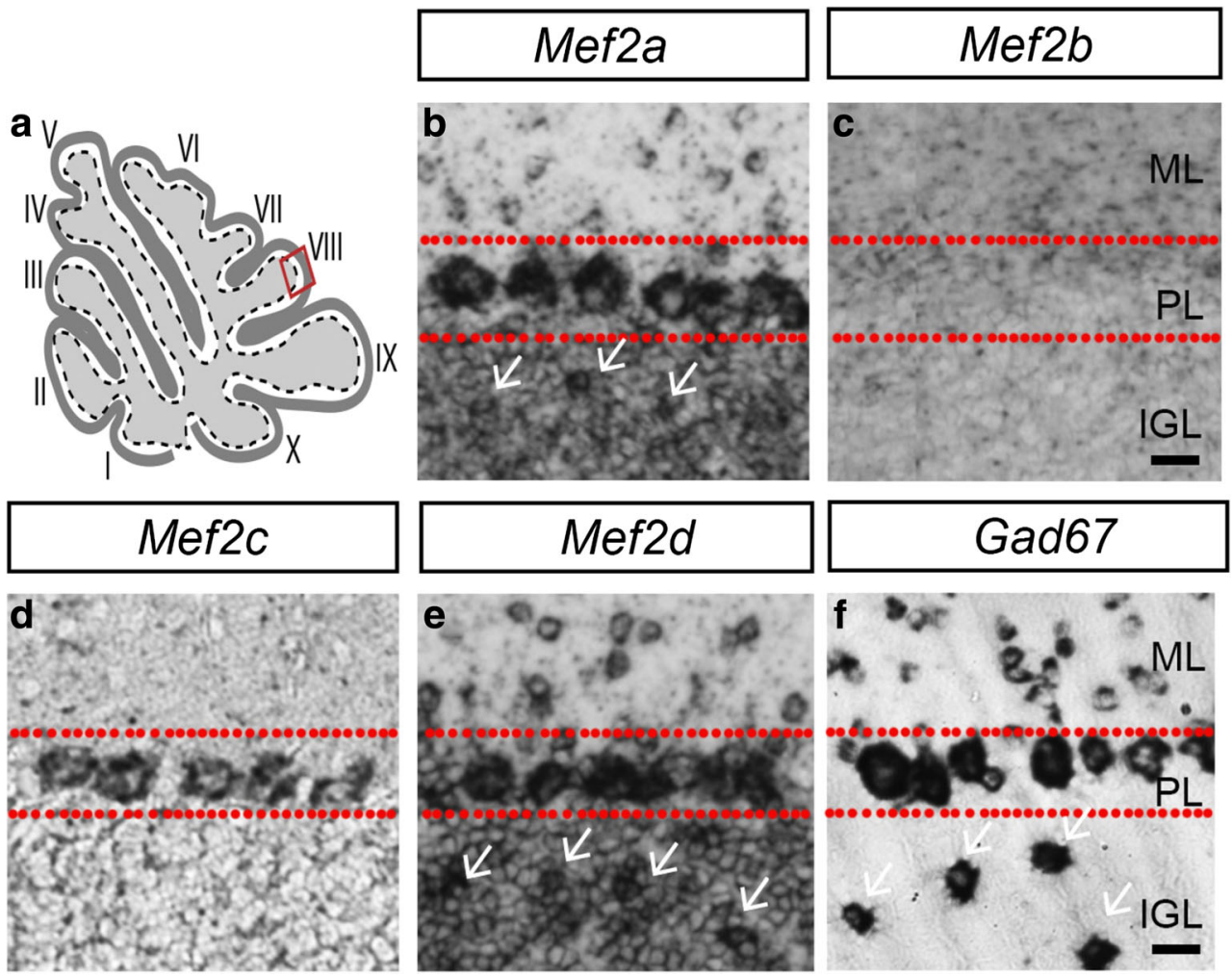

corresponds to Gad67 in the Purkinje cell layer, indicating that Mef $2 c$ is specifically expressed by Purkinje cells (Fig. 1b-f).

To confirm that the expression pattern of Mef2c protein is consistent with Mef2c RNA, we analyzed and compared the expression of Mef2c protein with known specific molecular markers of cerebellar neuronal subtypes. We first compared the expression of Mef2c with two calcium-binding proteins that define distinct GABAergic neuronal subpopulations in the cerebellar cortex: parvalbumin is expressed by stellate/ basket cells in the molecular layer and Purkinje cells in the Purkinje cell layer, whereas calbindin is expressed only by Purkinje cells [38]. At P60, Mef2c colocalizes with calbindin and parvalbumin in the Purkinje cell layer, but not parvalbumin in the molecular layer (Fig. 2a-f). Comparison of the expression of Mef2c with zebrin, which defines Purkinje cells restricted to cerebellar zones [39], shows that the expression of Mef2c does not correspond with zebrin, indicating that Mef2c is expressed by most Purkinje cells (Fig. S1). Next, we assessed the colocalization pattern of Mef2c with mGluR2 and NeuN, which label Golgi and granule cells, respectively [40, 41], and found that the expression of Mef $2 \mathrm{c}$ is not found in these two major neuronal subtypes in the internal granular layer, consistent with the lack of Mef $2 c$ RNA expression in granule cells and Golgi cells (Fig. 2g-1).

To determine the developmental expression profile of Mef2c in Purkinje cells, we analyzed and compared the expression of Mef2c and calbindin at embryonic and key postnatal developmental stages of Purkinje cells [28]. After their initial generation at E10.5, Purkinje cells are found in the white matter layer where they migrate radially towards the cortical surface between embryonic day (E) 13-E17 [27, 42]. We observed that Mef2c is not detected at either E15.5 or E18.5, when calbindin ${ }^{+}$Purkinje cells are localized in the white matter and early Purkinje cell layer (data not shown; Fig. 3a-d). During the first three postnatal weeks, Purkinje cells undergo local migration in the Purkinje cell layer to transit from multi-layer to a single layer and their dendrites undergo significant morphological changes [28]. At P0, we first detected colocalization of Mef2c with calbindin (Fig. 3e-h). From P7 to P21, the expression of Mef2c persists in Purkinje cells as they merge to form a single layer and extend their dendrites into the molecular layer (Fig. 3i-t). Altogether, through the analysis of the expression of Mef2 family of transcription factors, we show that Mef2c is unique in its absence of expression in neurons in the molecular and internal granular layers. Moreover, our results indicate that the expression of Mef2c tightly correlates with the early postnatal development of Purkinje cells, raising the possibility that Mef2c controls the migration and/or dendritic morphogenesis of Purkinje cells.

\section{Consequences of Mef2c Knockdown on the Development of Purkinje Cells}

Purkinje cells undergo dynamic morphological changes during the first three postnatal weeks [28, 43], and the 
Fig. 2 Mef2c is expressed specifically by Purkinje cells in the mature cerebellar cortex. a-c The expression of Mef2c (a, red) and calbindin (b, green)

colocalizes within Purkinje cells (c, merge). $\mathbf{d}-\mathbf{f}$ The expression of Mef2c (d, red) and parvalbumin (e, green) also colocalizes within Purkinje cells (f, merged), but not stellate/basket cells. g-i Mef2c expression (g, red) is absent in Golgi cells which are marked by mGluR2 (h, green) (i, merged). $\mathbf{j}-$ I The expression of Mef2c (j, red) also does not colocalize with $\mathrm{NeuN}$ (k, green) (l, merged) indicating a lack of expression in granule cells. Sagittal sections of lobule VIII from cerebellar vermis were used for this analysis. Complete circles represent cells with positive expression and broken circles indicate a lack of colocalization. PL, Purkinje cell layer; ML, molecular layer; IGL, internal granule layer. Age $=\mathrm{P} 60$ Scale bar $=10 \mu \mathrm{m}$
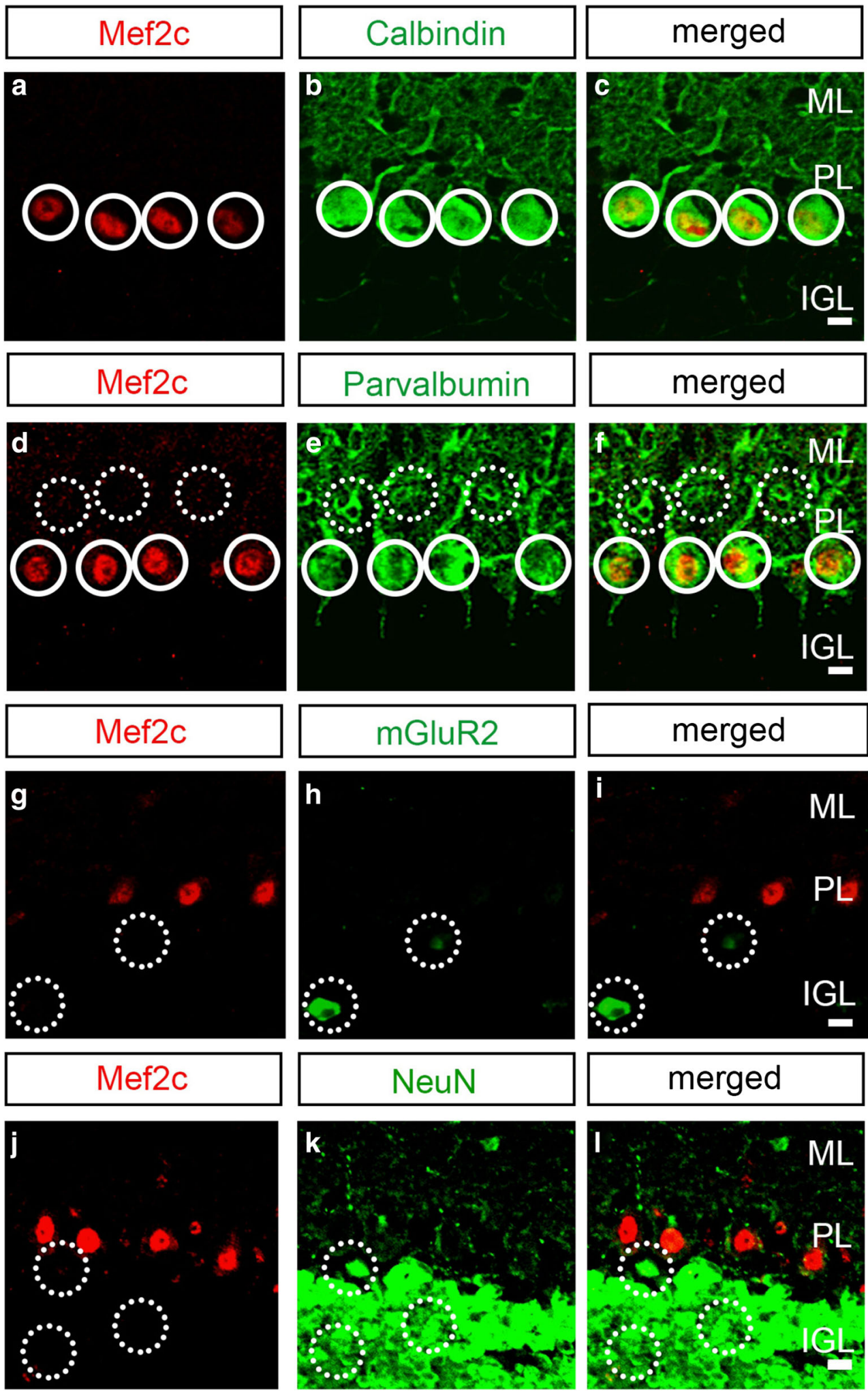

Parvalbumin
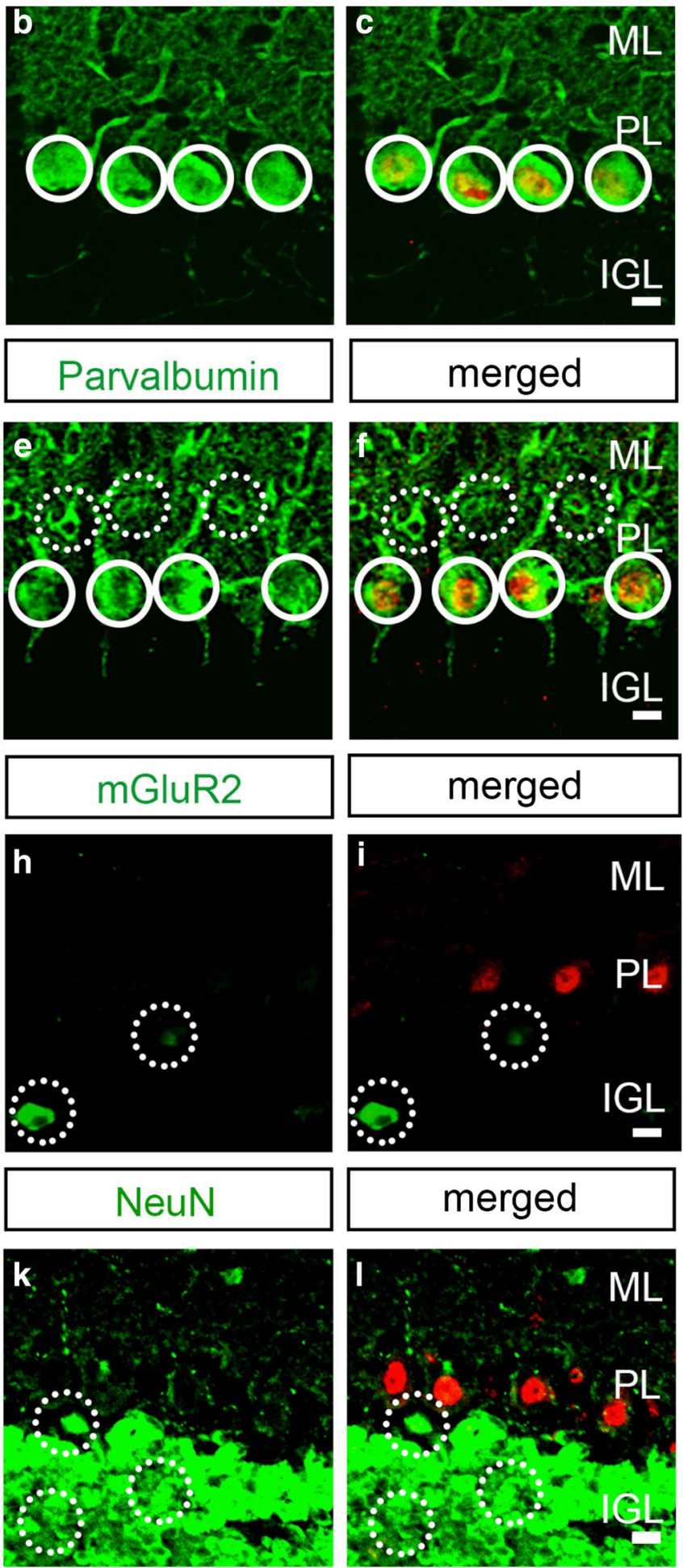

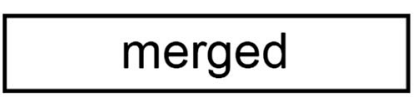

coincidence of the onset and sustained expression of Mef2c within this period suggests that Mef2c may contribute to aspects of the development and maturation of Purkinje cells. In order to explore this possibility, we utilized lentiviral- mediated expression of shRNA to knockdown the expression of Mef2c in Purkinje cells. To restrict our genetic manipulation and analysis to only Purkinje cells, we used a minimal region of the $\mathrm{L} 7$ promoter to drive expression of a reporter and 


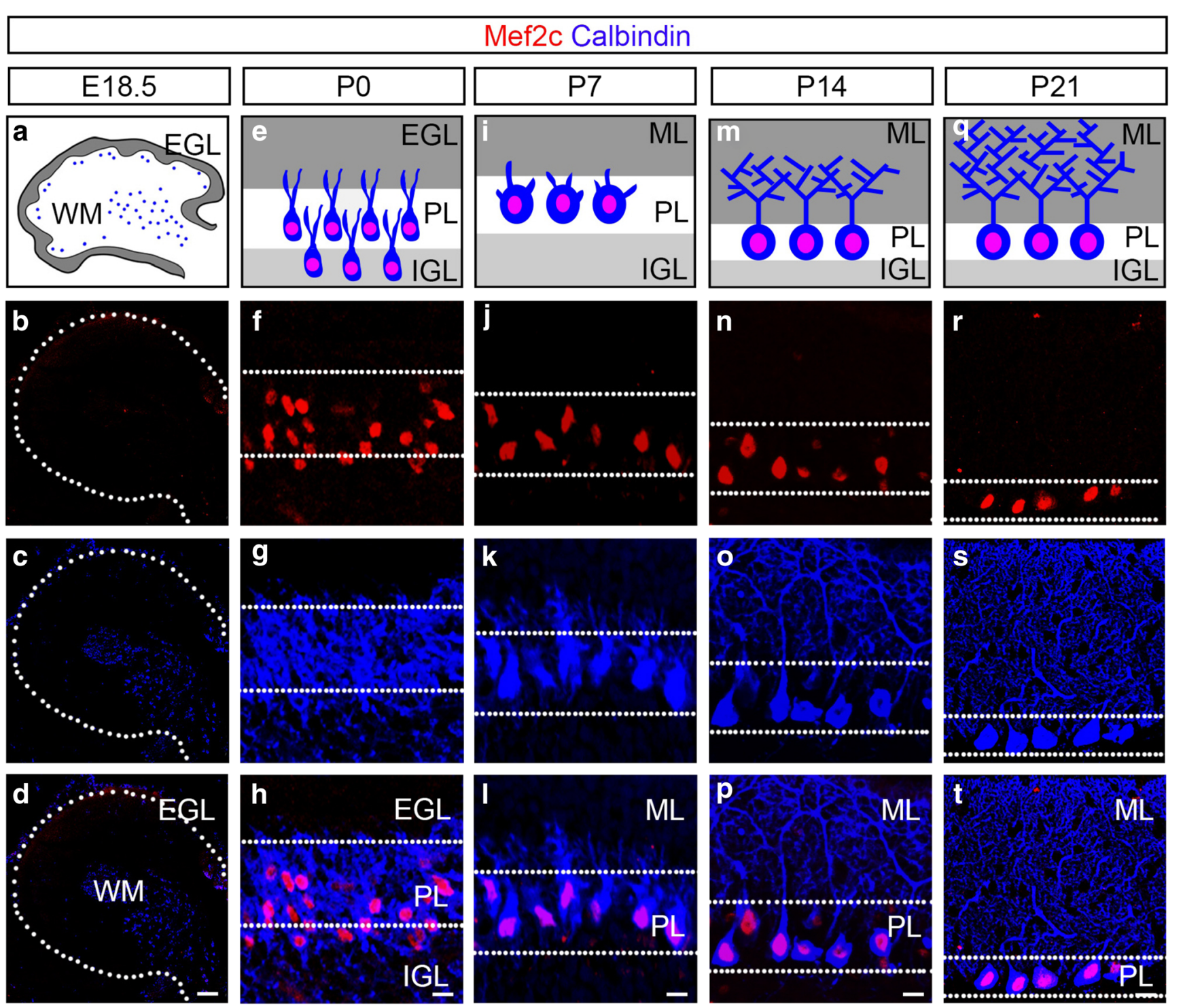

Fig. 3 The onset of Mef2c expression in developing Purkinje cells. a-d The expression of calbindin (blue), but not Mef2c (red), is detected at E18.5. $\mathbf{e}-\mathbf{h}$ Mef2c expression is first detected in Purkinje cells at P0. $\mathbf{i}-\mathbf{t}$ Mef2c (red) continues to be expressed in calbindin ${ }^{+}$Purkinje cells (blue)

shRNA against Mef2c [32]. Short-hairpin RNA (shRNA) for control (scrambled) and for Mef2c knockdown were generated and placed downstream of the truncated L7-CMV promoter in a miRNA cassette (Fig. 4a). We infected Purkinje cells between $\mathrm{P} 1-\mathrm{P} 7$ and analyzed their morphological properties and organization within the cerebellar cortex at P14 or P21 (Fig. 4b). Infection of P1 pups with lentiviral constructs results in specific expression of GFP in Purkinje cells and permits the visualization and reconstruction of the dendritic pattern (Fig. $4 c-f)$. We analyzed the level of Mef2c expression in $\mathrm{GFP}^{+}$ neurons (Fig. 4g-1) and found that shRNA-mediated Mef2c knockdown results in a $\sim$ three-fold decrease in Mef2c expression compared to control (Fig. 4m). The inability of Mef2c shRNA to knockdown Mef2a indicates that it is capable of selectively reducing the level of Mef2c (Fig. S4). Thus, we at P7 (i-l), P14 (m-p) and P21 (q-t). Merged (d, h, l, p, t). PL, Purkinje cell layer; ML, molecular layer; IGL, internal granule layer; E, embryonic day; P, postnatal day. Scale bar $=10 \mu \mathrm{m}$

show that lentiviral-mediated transduction in combination with the use of the $\mathrm{L} 7$ minimal promoter permits both efficient knockdown of Mef2c and analysis of the functional relevance of Mef2c specifically in developing Purkinje cells.

The soma size of Purkinje cells increases rapidly and multiple dendrites are pruned into one single primary dendrite during the first two postnatal weeks of cerebellar development $[28,44]$; and, the soma size and initial dendritic pruning of Purkinje cells have been shown to be dependent on transcription factors [23, 45]. We first examined whether Mef2c knockdown influences the general morphological properties of Purkinje cells and found that the mean soma size of Purkinje cell soma at P21 is not affected by Mef2c knockdown at P1 (Fig. S2a-f, h). A close examination of the primary dendrites of Purkinje cells also indicates that Mef2c knockdown does 
a

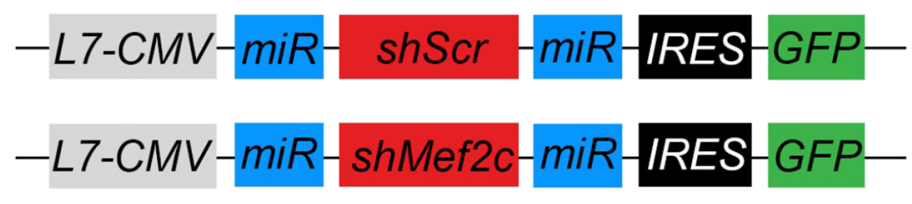

b

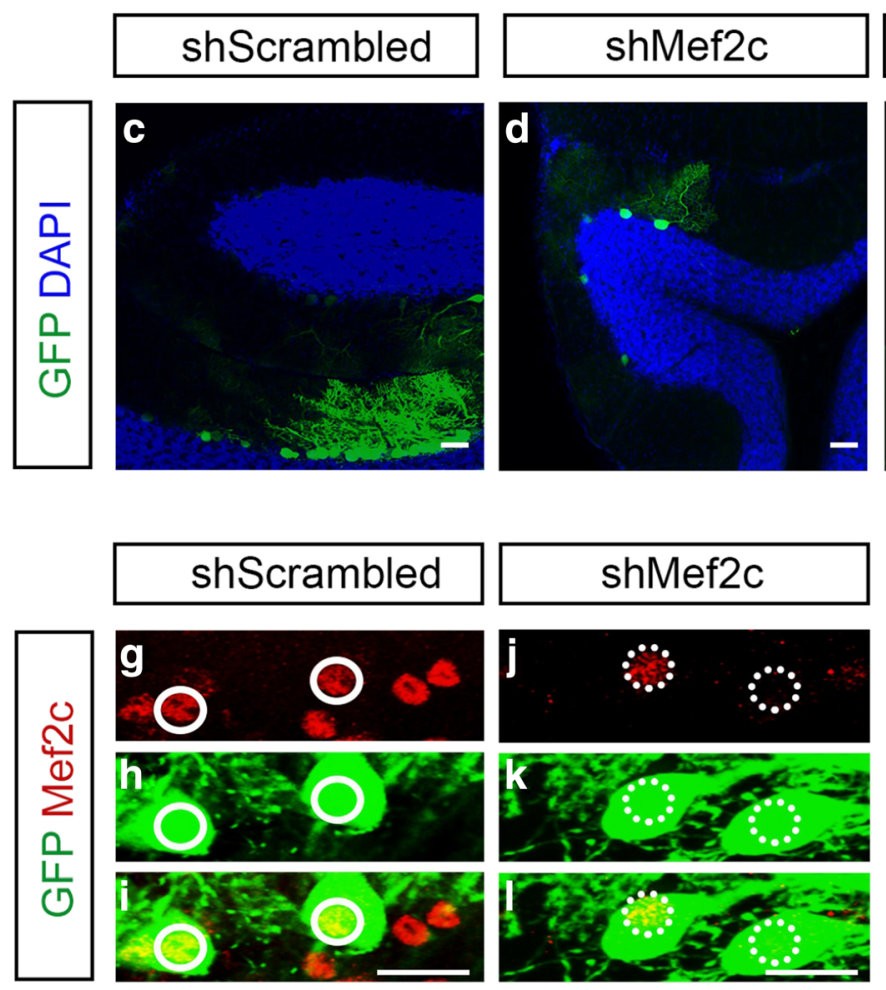

Fig. 4 Selective labeling of Purkinje cells and shRNA-mediated knockdown of Mef2c. a Schematic diagram of the lentiviral shRNA constructs for control and Mef2c knockdown. b Schematic diagram showing key developmental stages of Purkinje cell dendrites. Green arrow indicates time of transduction (at P1, P3, and P7) and red arrow indicate time of analysis (at either P14 or P21). c-d Analysis of GFP (green) and DAPI (blue) in Purkinje cells after transduction with shScrambled (left) and shMef2c virus (right). e-f An infected Purkinje cells was traced (e, magenta) and reconstructed using the simple neurite

not result in improper pruning of perisomatic dendrites (Fig. S2a-f). Additionally, we did not find evidence of GFAP ${ }^{+}$reactive gliosis, which has been associated with Purkinje cell death (Fig. S2i-1) [46]. The transition from multi-layers to a single layer of Purkinje cells occurs between P0 and P10 in the developing cerebellum [47]. Mef2c knockdown does not affect the formation of $\mathrm{GFP}^{+}$Purkinje cells into a single layer or the position of $\mathrm{GFP}^{+}$cells in relation to the edge of the molecular layer (Fig. S2m-t). Together, these results indicate that the loss of Mef2c does not influence the general growth or health of Purkinje cells and does not appear to play a role in the initial pruning of dendrites or postnatal migration of Purkinje cells.
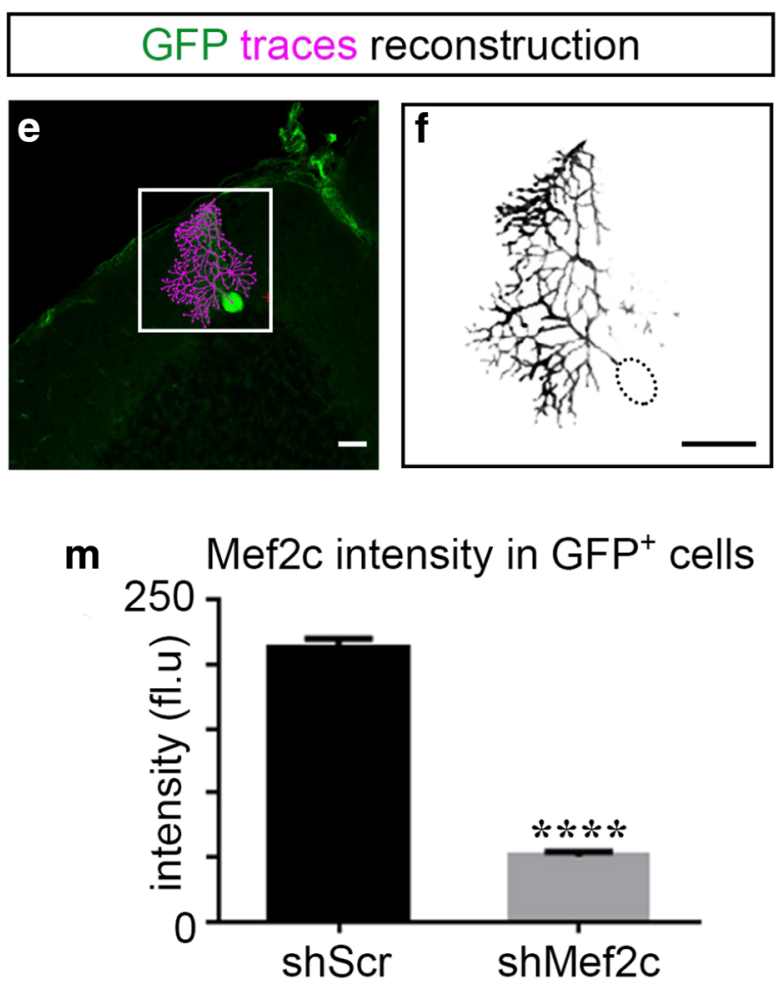

tracer plugin in Fiji (f). g-l Analysis of Mef2c (red) in $\mathrm{GFP}^{+}$Purkinje cells transduced with control (g-i) and knockdown lentivirus (j-l). m shRNAmediated knockdown of Mef2c results in reduction of the expression level of Mef2c (shScrambled 212.9 $\pm 6.913, N=13, n=38$; shMef2c $50.48 \pm 3.581, N=15, n=36, * * * * P<0.0001)$. CMV, cytomegalovirus; miR, micro RNA; shRNA, short-hairpin RNA; IRES, internal ribosome entry site; GFP, green fluorescent protein; Data values $=$ mean \pm SEM, Student's $t$ test. Scale bar for $\mathbf{c}-\mathbf{d}=50 \mu \mathrm{m}, \mathbf{e}-\mathbf{l}=$ $20 \mu \mathrm{m}$

\section{Knockdown of Mef2c Expression Results in an Increase in Dendritic Complexity of Purkinje Cells}

Studies of the underlying brain disruptions in neurological disorders, such as autism, in patients and mouse models have uncovered changes in the morphology of dendrites and the number of dendritic spines in Purkinje cells [22, 23, 48, 49]. The development and maintenance of dendritic morphology and spine density influence Purkinje cell function since extensive excitatory and inhibitory processes synapse on the elaborate dendritic tree [50]. After transitioning from multiple perisomatic processes to a single apical stem, rapid branching/elaboration of the apical stem dendritic tree takes 
place during the second and third postnatal week [28]. In order to determine whether and how Mef2c regulates the morphology of Purkinje cell dendrites, we knocked down Mef2 expression at two different stages and analyzed the dendritic tree of $\mathrm{GFP}^{+}$Purkinje cells by Sholl analysis (see "Materials and Methods").

Knockdown of Mef2c expression at P1 results in a $61 \%$ increase in the total number of intersections from the single apical stem dendrite of Purkinje cells when analyzed at P14 (Fig. 5a, b). The total length of dendrites is increased by $38 \%$ without any changes to the area or height of the dendritic tree after Mef2c knockdown (Fig. 5 c, d; Fig. S3). Additionally, the distance of maximum intersections move from a more distal position (Fig. 5e; Fig. S3). In order to assess the contribution of Mef2c in Purkinje cell development beyond P14, and determine whether the effects of Mef2c knockdown on the morphology of Purkinje cells persists after P14, we analyzed the number of intersections and total length of dendritic trees at P21. Similar to the observations at P14, we saw a marked increase in the total number of intersections and dendritic length of Purkinje cell dendrites at P21 after knockdown of Mef2c at P1 (data not shown), indicating this morphological phenotype persists beyond the first two postnatal weeks. Because we did not see abnormal pruning of the multi-perisomatic dendrites after Mef2c knockdown (Fig. S2), this result suggests Mef2 selectively regulates branching, but not pruning, of Purkinje cell dendrites.

At the end of the first postnatal week, Purkinje cells begin to have a single apical dendritic stem and undergo an increase in branching over the next 2 weeks that corresponds to key developmental events, such as completion of parallel/climbing fiber elimination and formation of functional GABAergic synapses by stellate and basket cells [28]. In order to assess whether Mef2c has an ability to influence branching of Purkinje cell dendrites after the first postnatal week, we analyzed the dendritic trees of Purkinje cells at P21 after Mef2c knockdown at P7. Knockdown of Mef2c knockdown at P7 results in a $36 \%$ increase in the number of intersections of Purkinje cell dendrites (Fig. 5f, g). However, the total length and area of dendrites, as well as the distribution of intersections, are not significantly different between experimental groups (Fig. 5h-j; Fig. S3). Taken together, we show that the loss of Mef2c leads to an increase in branching of Purkinje cell dendrites, suggesting that Mef2c controls dendritic complexity by restricting the branching and arborization of Purkinje cell dendrites. Additionally, because the changes corresponding to Mef2c knockdown at P7 is less severe than knockdown at P1, there may be a critical period of the influence of Mef2c on dendritic development.
Knockdown of Mef2c Expression Results in an Increase in the Number of Terminal Spines and Changes in Excitatory and Inhibitory Synaptic Protein Localization on Purkinje Cell Dendrites

Early postnatal spinogenesis of Purkinje cells can occur without excitatory input and is presumed to be regulated by cellautonomous mechanisms [28]. Additionally, genetic manipulation of factors important for actin polymerization has shown that loss of spines can occur without any changes to the growth and morphology of the dendritic trees of Purkinje cells [28], suggesting spinogenesis and dendritic morphogenesis are regulated by independent pathways. To assess whether Mef2c plays a role in formation of spines, we knocked down Mef2c expression in P1 mice and assessed the number and length of spines on terminal dendrites of $\mathrm{GFP}^{+}$neuron at P14. We were only able to detect spiney branchlets in $\mathrm{GFP}^{+}$neurons even though Purkinje cells are known to possess two types of spines: thorns, sites of climbing fiber contacts located mostly on primary and secondary dendrites, and spiney branchlets, sites of parallel fiber contacts found on tertiary and terminal dendrites [28]. The loss of Mef2c during the first postnatal week of Purkinje cell development results in a $12 \%$ increase in the total number of spiny branchlets in the distal part of Purkinje dendritic tree compared to control (Fig. 6a-c, e-g, d). However, the loss of Mef2c does not impact the length of spines (Fig. 6h). Although only a modest effect on the number of spines is observed, our result indicates that the expression of Mef2c is required for maintenance of an appropriate density of Purkinje cell spines during early postnatal development.

Loss of Mef2c leads to an imbalance of excitatory and inhibitory synapse densities in cortical and hippocampal neurons [6, 34]; however, these studies focused their analysis only on excitatory neurons. In order to determine whether Mef2c plays a similar role in GABAergic neurons, we analyzed the localization of vGluT1 and vGluT2 on $\mathrm{GFP}^{+}$Purkinje cell dendrites. vGluT1 and vGluT2 are molecular markers for glutamatergic parallel and climbing fiber synaptic puncta, respectively [51]. We observed that the loss of Mef2c resulted in a $28 \%$ increase of vGluT1 puncta at P14 and a $\sim 15 \%$ increase in vGluT1 puncta at $\mathrm{P} 21$ on $\mathrm{GFP}^{+}$Purkinje cell dendrites (Fig. 7a-j). Mef2c knockdown at P1 did not result in significant changes of vGluT2 puncta localization at P14 (Fig. 7k-n, $\mathrm{s}$ ), but lead to $\mathrm{a} \sim 50 \%$ reduction of vGluT2 puncta at $\mathrm{P} 21$ compared to control (Fig. 7o-r, t). The localization of both vGluT1 and vGluT2 puncta on Purkinje cell soma is not affected after Mef2c knockdown compared to control (Fig. S5 at). Thus, our results indicate a requirement of $M e f 2 c$ in a GABAergic neuronal subtype in the maintenance of proper excitatory input to Purkinje cells.

In order to examine consequences of Mef2c knockdown at P1 on inhibitory inputs on Purkinje cells, we analyzed the 


\section{a}

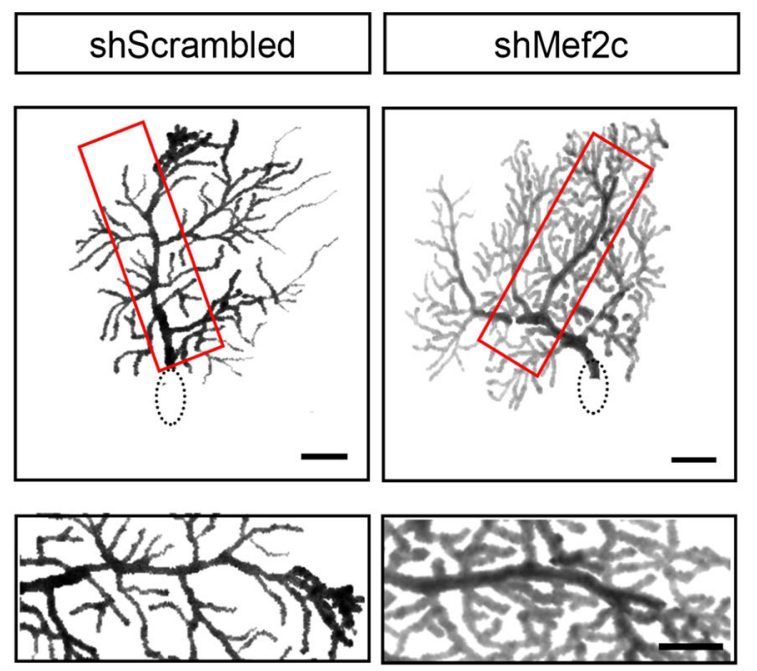

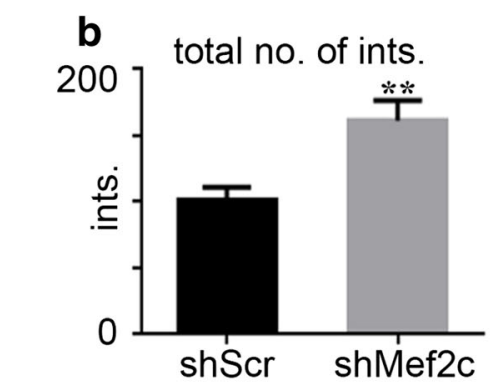

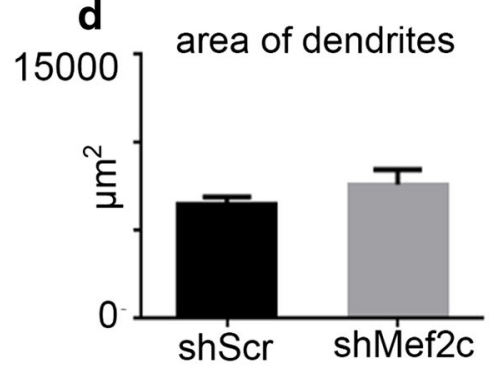

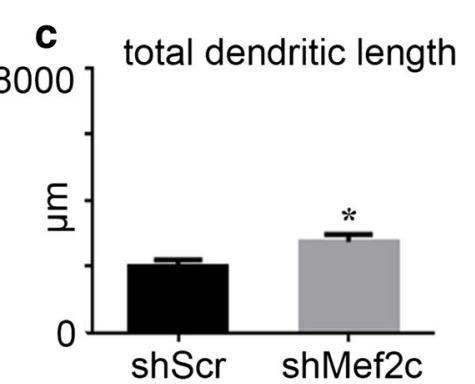

e

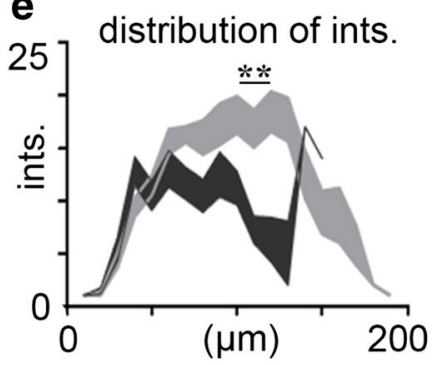

f

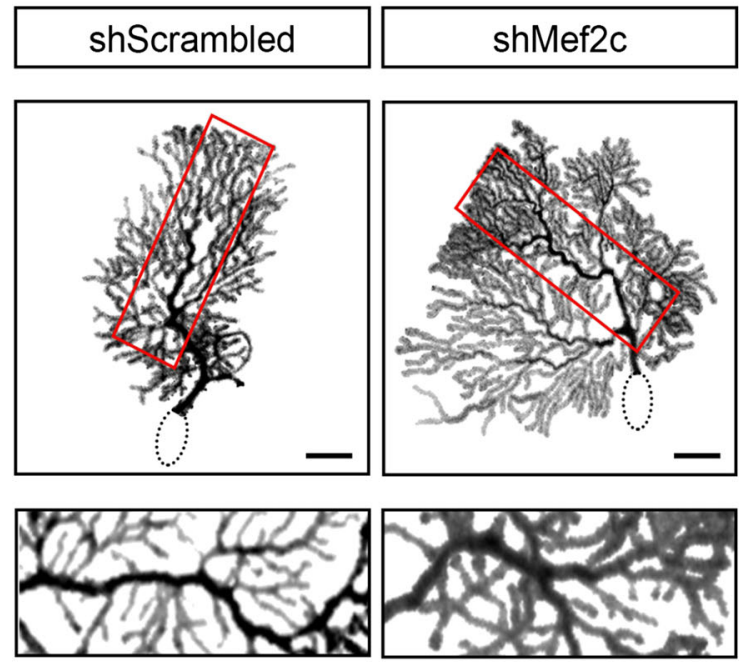

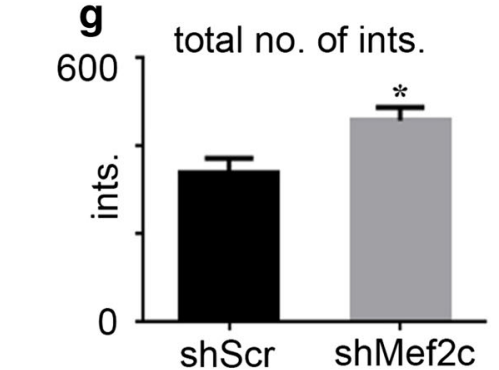

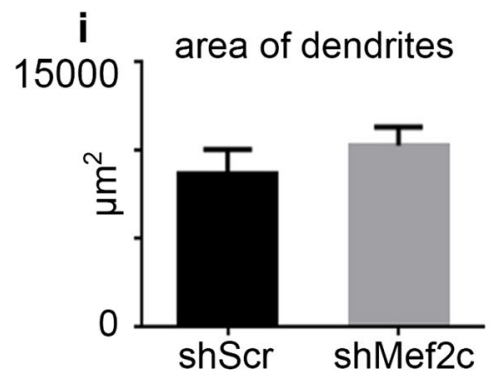

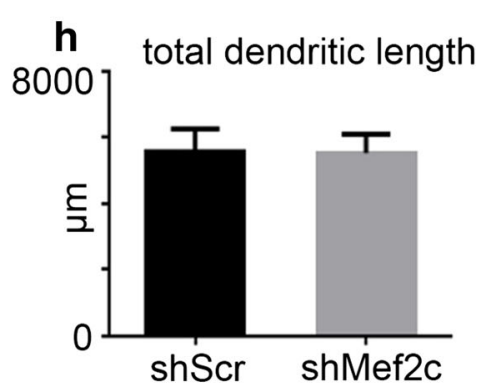

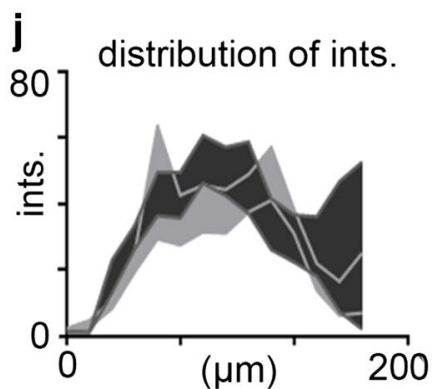

Fig. 5 Mef2c knockdown results in an increase in complexity of Purkinje cell dendrites. a Representative traces of a control and shMef2c Purkinje cell at P14. b Analysis of the total number of intersections in control (black) and Mef2c knockdown (gray) Purkinje cells (shScrambled $100.5 \pm 10.34, n=11 ;$ shMef2c $161.3 \pm 14.69, n=18 ; * * P=0.0063$; $N=7$ for shScrambled, 10 for shMef2c). c Analysis of the total dendritic length in control and Mef2c knockdown Purkinje cells (shScrambled $1974 \pm 209.6, n=10 ;$ shMef2c 2737 $\pm 222.4, n=16$; $* P=0.0285 ; N=7$ for shScrambled, 10 for shMef2c). d Analysis of the area of Purkinje cell dendrites (shScrambled $6393 \pm 473.1, n=14$; shMef2c 7552 $\pm 852.8, n=19 ; P=0.2901 ; N=7$ for shScrambled, 10 for shMef2c). e Analysis of the distribution of dendritic intersections along the somato-dendritic axis shows a higher number of intersections in Mef2c knockdown Purkinje cells at $110 \mu \mathrm{m}$ and $120 \mu \mathrm{m}$ from the soma (at $110 \mu \mathrm{m} * * P=0.0009$; at $120 \mu \mathrm{m} * * P=0.0008$ ). f Representative

incidence of Gad67 puncta on $\mathrm{GFP}^{+}$Purkinje cells at P14 and $\mathrm{P} 21$. At P14, we observed a $~ 2.6$-fold increase in Gad67 puncta on Purkinje cell dendrites (Fig. 8 a-d, i), and a 2-fold traces of a control and shMef2c Purkinje cell at P21. g Analysis of the total number of intersections in control (black) and Mef2c knockdown (gray) Purkinje cells (shScrambled 107.2 $\pm 10.73, n=5$; shMef2c 294.5 $\pm 51.00, n=4 ; * P=0.005 ; N=3$ for shScrambled, 3 for shMef2c). $\mathbf{h}$ Analysis of the total dendritic length in control and Mef2c knockdown Purkinje cells (shScrambled 5576 $\pm 673.3, n=6$; shMef2c $5513 \pm 576.9$, $\mathrm{n}=6 ; P=0.9448 ; N=3$ for shScrambled, 3 for shMef2c). i Analysis of the area of Purkinje cell dendrites (shScrambled $8625 \pm 1390, n=9$; shMef2c $10222 \pm 1058, n=8 ; P=0.3844 ; N=3$ brains for shScrambled, 3 brains for shMef $2 \mathrm{c}$ ). $\mathbf{j}$ Analysis of the distribution of dendritic intersections along the somato-dendritic axis did not reveal any significant differences between control and shMef2c Purkinje cells. Scr, scrambled; PC, Purkinje cell; sh, short-hairpin RNA; ints., intersections; P, postnatal. Data values $=$ mean \pm SEM, Student's $t$ test. Scale bar $=20 \mu \mathrm{m}$

increase in Gad67 puncta after Mef2c knockdown compared to control (Fig. 8e-h, j). At P21, the loss of Mef2c did not result in significant changes in Gad67 puncta localization in 

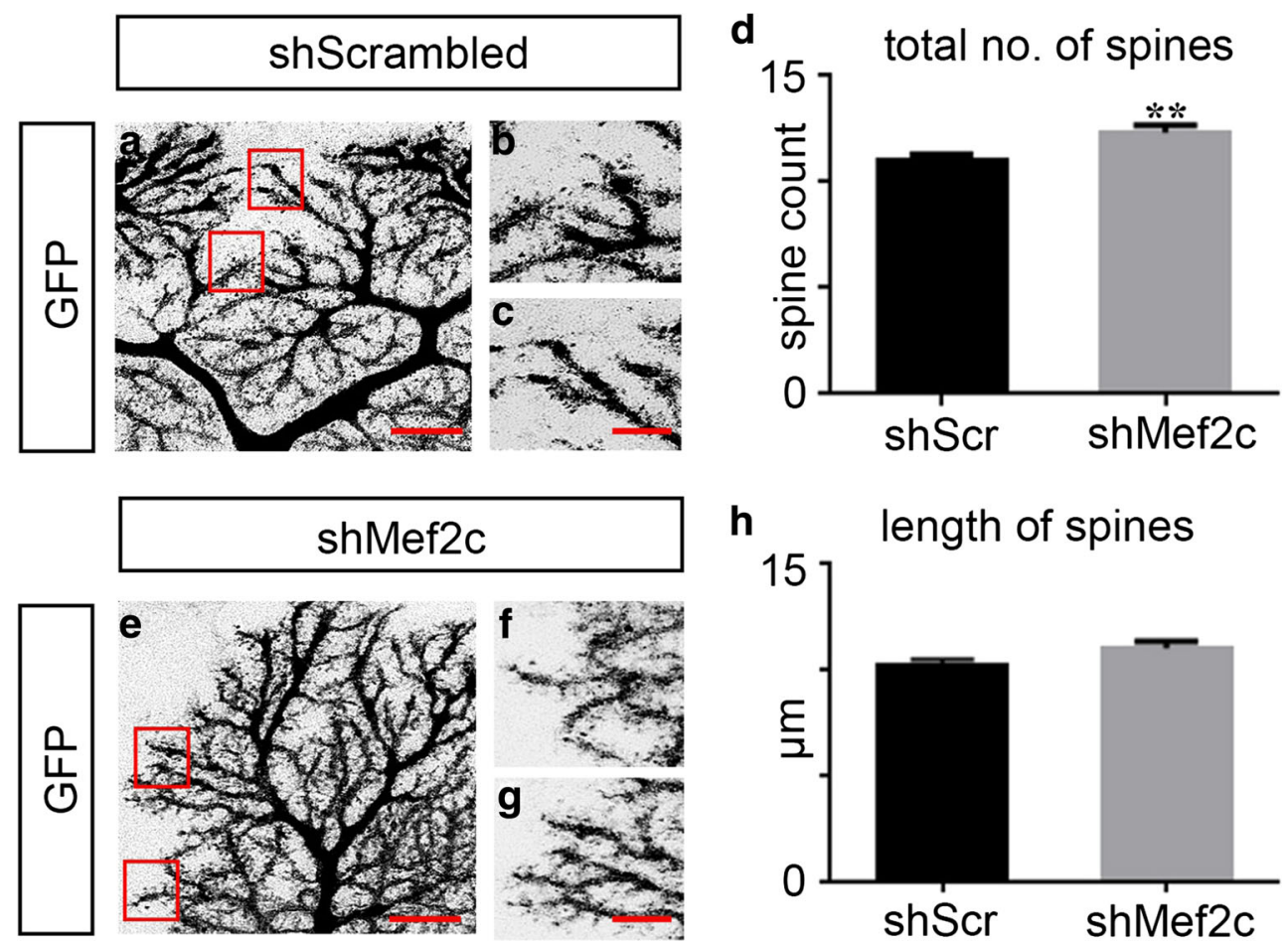

Fig. 6 Mef2c knockdown results in an increase in number of spines on Purkinje cell dendrites. a-c, e-g Representative images of control (a, higher magnification in $\mathbf{b}, \mathbf{c})$ and shMef2c Purkinje cells (e, higher magnification in $\mathbf{f}, \mathbf{g}$ ). $\mathbf{d}$ Analysis of the total number of spines per 10$\mu \mathrm{m}$ length of dendrite in control and shMef2c Purkinje cells (shScrambled $11.00 \pm 0.2837, n=30$; shMef2c $12.33 \pm 0.3368, n=30$;
** $P=0.0037 ; N=3$ per experimental group). h Analysis of the average length of spines in control and shMef2c Purkinje cells (shScrambled $10.14 \pm 0.2878, n=60 ; \operatorname{shMef2c} 10.94 \pm 0.3413, n=60 ; P=0.0735$; $N=3$ per experimental group). Scr, scrambled, GFP, green fluorescent protein, sh, short-hairpin RNA. Data values $=$ mean \pm SEM, Student's $t$ test. Scale bar for $\mathbf{a}, \mathbf{e}=10 \mu \mathrm{m}, \mathbf{b}, \mathbf{c}, \mathbf{f}, \mathbf{g}=5 \mu \mathrm{m}$ the soma (Fig. 8o-r, t), but resulted in a $\sim 66 \%$ increase in Gad67 puncta compared to scrambled (Fig. 8k-n, s). Thus, our results indicate that Mef2c has the ability to regulate both inhibitory and excitatory input onto Purkinje cells and may play an important role in maintaining the proper balance between parallel and climbing fiber input in developing and mature Purkinje cells. Taken together, we provide evidence that the specific expression of Mef2c is critical for maintaining the complexity of Purkinje cell dendrites during the first three postnatal weeks of development and is an important regulator of synaptic input.

\section{Discussion}

In this study, we examined the role of Mef2c, a transcription factor implicated in a number of neurological disorders through characterization of the expression and functional relevance of Mef2c in the developing cerebellar cortex. We found that Mef2c is expressed specifically in Purkinje cells and that the onset of Mef2c expression occurs between E18.5 and $\mathrm{P} 0$ and persists into adulthood. The loss of Mef2c expression during the first or second postnatal week results in an increase in dendritic arborization, without impact on the general growth or migration of Purkinje cells. The loss of Mef2c expression resulting in an increase in the number of spines and changes in both excitatory and inhibitory puncta localization is suggestive of a potential imbalance in excitatory and/or inhibitory synaptic input. Thus, our study provides details of the specific expression and function of Mef2c in cerebellar Purkinje cells and lays the groundwork for future examination of the behavioral and electrophysiological consequences of the specific manipulation of Purkinje cell dendritic tree. Moreover, we demonstrate that the reduced expression of a transcription factor implicated in neurological disorders in a GABAergic neuronal subtype may perturb neuronal connectivity, which could lead to pathogenesis of cerebellarassociated disorders.

\section{Mef2c Is an Essential Regulator of the Development of Purkinje Cell Dendrites and Spines}

Transcription factors play critical roles in the specification of neuronal subtypes and regulation of morphology and synaptic formation in the developing nervous system [52-54], and many continue to exert their influence in an activitydependent manner for the maintenance and refinement of neuronal processes in mature animals [55-57]. In comparison to the large number of transcriptional programs important for generation and development of excitatory granule cells in 

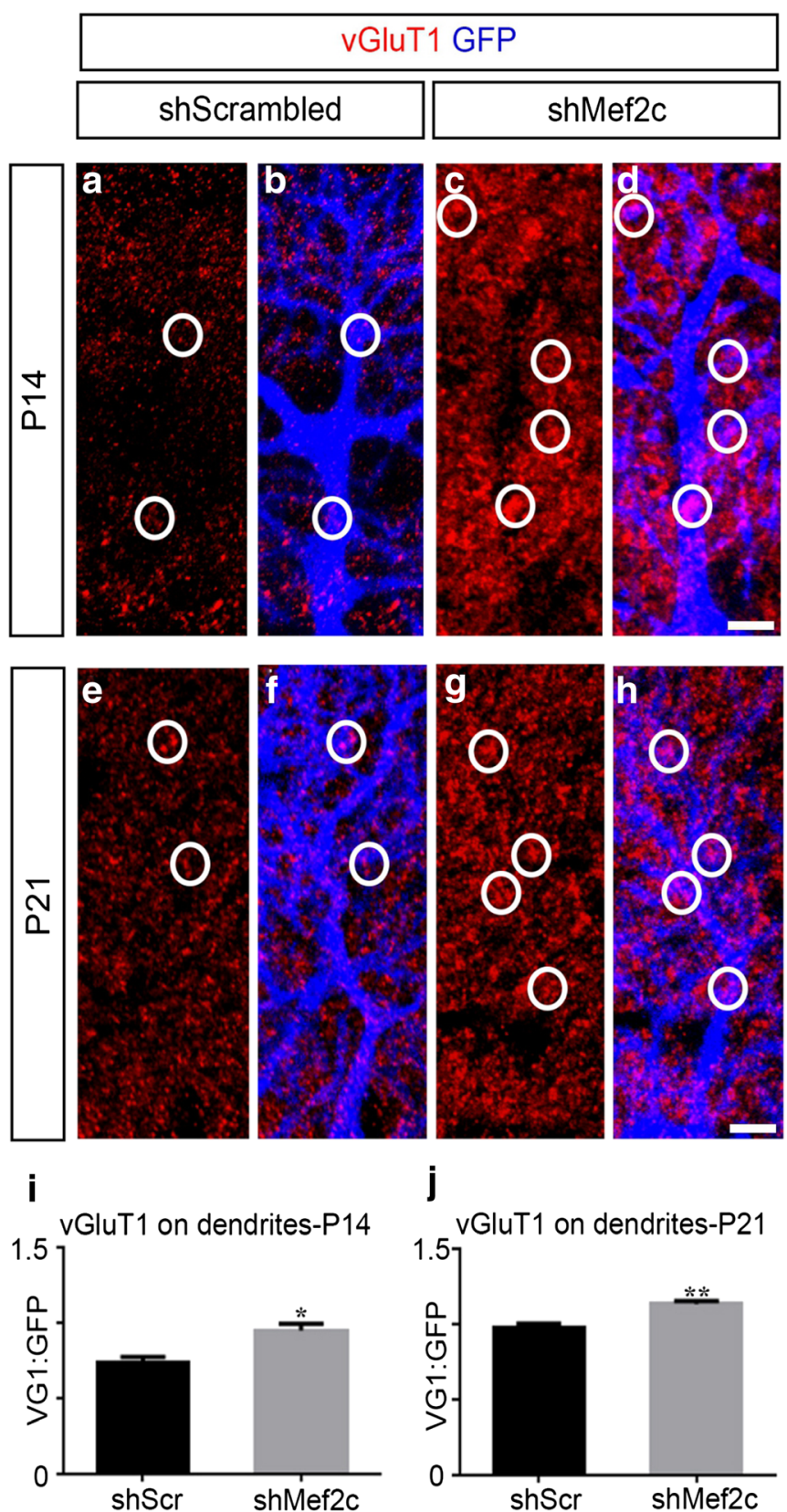

Fig. 7 Mef2c knockdown results in an increase in vGluT1 and decrease in vGluT2 puncta on Purkinje cell dendrites. a-d Representative images of vGluT1 puncta (red, a) on $\mathrm{GFP}^{+}$dendrites (blue, b) of a control Purkinje cell, and vGluT1 puncta (red, c) on $\mathrm{GFP}^{+}$dendrites (blue, d) of a shMef2c Purkinje cell at P14 after viral transduction at P1. i Analysis of the coincidence of vGluT1 puncta on the dendrites of control and shMef2c Purkinje cells expressed as a ratio (shScrambled $0.7360 \pm$ $0.03347, n=10 ;$ shMef2c $0.9460 \pm 0.04532, n=10 ; * P=0.0015 ; N=4$ for shScrambled; 5 for shMef2c). $\mathbf{e}-\mathbf{h}$ Representative images of vGluT1 puncta (red, e) on $\mathrm{GFP}^{+}$dendrites (blue, $\mathbf{f}$ ) of a control Purkinje cell, and vGluT1 puncta (red, $\mathbf{g}$ ) on $\mathrm{GFP}^{+}$dendrites (blue, $\mathbf{h}$ ) of a shMef2c Purkinje cell at P21 after viral transduction at P1. i Analysis of the coincidence of vGluT1 puncta on the dendrites of control and shMef2c Purkinje cells expressed as a ratio (shScrambled $0.9760 \pm 0.02477, n=18$; shMef2c $1.129 \pm 0.01975, n=16 ; * P=0.0001 ; N=5$ for shScrambled; 5 for shMef2c). k-n Representative images of vGluT2 puncta (red, k) on
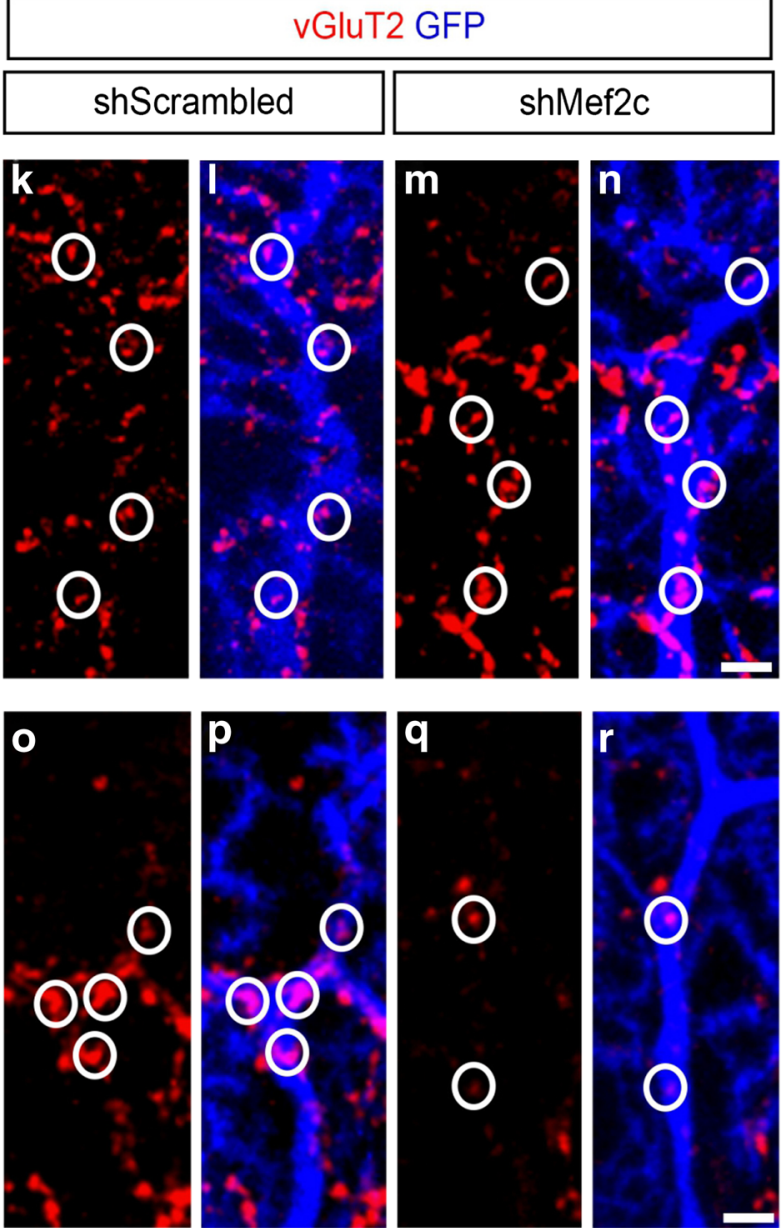

$\mathbf{S}$

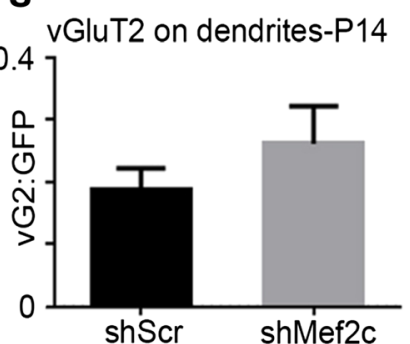

$\mathbf{t}$

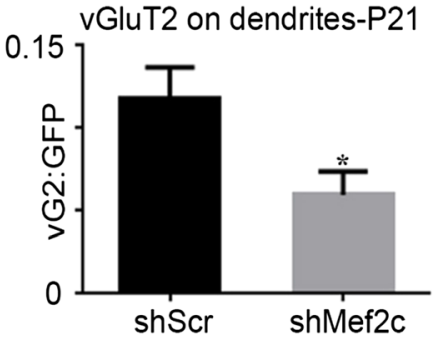

$\mathrm{GFP}^{+}$dendrites (blue, l) of a control Purkinje cell, and vGluT2 puncta (red, m) on $\mathrm{GFP}^{+}$dendrites (blue, $\mathbf{n}$ ) of a shMef2c Purkinje cell at P14 after viral transduction at P1. s Analysis of the coincidence of vGluT2 puncta on the dendrites of control and shMef2c Purkinje cells expressed as a ratio (shScrambled $0.1880 \pm 0.03289, n=10 ;$ shMef2c $0.2607 \pm$ $0.06061, n=15 ; P=0.3693 ; N=5$ for shScrambled; 7 for shMef2c). $\mathbf{o}$ $\mathbf{r}$ Representative images of vGluT2 puncta (red, $\mathbf{0}$ ) on $\mathrm{GFP}^{+}$dendrites (blue, $\mathbf{p}$ ) of a control Purkinje cell, and vGluT2 puncta (red, $\mathbf{q}$ ) on $\mathrm{GFP}^{+}$ dendrites (blue, r) of a shMef2c Purkinje cell at P21 after viral transduction at P1. $\mathbf{t}$ Analysis of the coincidence of vGluT2 puncta on the dendrites of control and shMef2c Purkinje cells expressed as a ratio ( shScrambled $0.1167 \pm 0.01944, n=12$; shMef2c $0.05875 \pm 0.01432$, $n=15 ; * P=0.0433 ; N=5$ for shScrambled; 7 for shMef2c). vGluT1/ vG1, vesicular glutamate transporter 1; vGluT2/vG2, vesicular glutamate transporter 2. Data values $=$ mean $\pm \mathrm{SEM}$, Student's $t$ test. Scale bar $=$ $5 \mu \mathrm{m}$ 
the cerebellum [58-62], relatively few transcription factors have been identified for cerebellar inhibitory neurons. The specification and differentiation of cerebellar GABAergic neurons require transcription factors Ptfla and Tfap2a/b [63-65]. The generation and differentiation of Purkinje cells depend on Olig2, Lhx1/5, Corl2/Skor2, and ROR $\alpha$; however, the expression of Olig2 is turned off during embryonic stages and the expression of $\operatorname{Lhx} 1 / 5$ and ROR $\alpha$ is not restricted to Purkinje cells [45, 66-69]. Similar to Corl2/Skor2, our characterization of the expression and functional relevance of Mef2c provides a genetic entry point for the specific interrogation of Purkinje cell differentiation and Purkinje cellmediated function. Moreover, our study provides evidence that in addition to excitatory neurons, Mef2c controls the development and, perhaps, maintenance of inhibitory neuronal processes.

The assembly of functional circuits in the brain requires proper dendritic formation and morphogenesis for integration of synaptic input, and these processes are tightly regulated by a number of transcription factors [70]. Even though Purkinje cells are born during embryonic stages, the growth and expansion of their dendritic tree occur during the first 3 weeks in postnatal mice [71]. We show that the onset of Mef2c expression coincides with the period of dynamic change in Purkinje cell dendrite development (Fig. 2) and provide evidence that the expression of Mef2c is critical for regulating the complexity of dendritic patterns. Because the expression of Corl2/ Skor2 is turned on at E12.5, in addition to dendrite development, Corl2/Skor2 is required for early specification and migration of Purkinje cells [66, 67]. Similarly, ROR $\alpha$ expression comes on in Purkinje cells at E13 and regulates the survival of Purkinje cells as well as the pruning, formation, and maintenance of dendrites [45, 72]. In contrast to both Corl2/Skor2 and ROR $\alpha$, the loss of Mef2c from Purkinje cells disrupts dendritic and spine formation without affecting migration, somatic pruning, or survival. Additionally, the loss of ROR $\alpha$ results in a decrease in dendritic complexity, whereas the loss of Mef2c results in an increase in complexity, suggesting opposing roles of these two transcription factors. Therefore, likely due to postnatal onset of expression, Mef2c appears to be a specific regulator of dendritic formation and morphogenesis.

\section{Distinct Expression and Function of Mef2 Family of Transcription Factors in the Developing Cerebellum}

The cerebellum has been identified as one of the brain regions of humans and mice with high expression level of Mef 2 family of transcription factors $[13,14,36,73,74]$, suggesting that they coordinate aspects of development and maintenance of the cerebellum. With the exception of Mef2b, all members of this family are expressed in the mouse cerebellum $[36,73,74]$. The expression of both Mef2a and Mef2d are first detected in the cerebellum at late embryonic stages in Purkinje and granule cells consistent with our results (Fig. S1) [73, 74], while Mef2c appears to be expressed predominantly by Purkinje cells [36]. However, the resolution of the analysis and lack of colocalization with neuronal subtype-specific molecular markers preclude conclusions about the specificity of Mef2c expression in Purkinje cells. For instance, whether Mef 2 transcription factors are expressed in interneurons in the molecular and/or internal granular layer has not been determined. We observe that both Mef2a and Mef2d expression, but not Mef2c, are found in the molecular layer, and that Mef2a is expressed by Parvalbumin ${ }^{+}$molecular layer interneurons (Fig. 1; data not shown). Importantly, our expression analysis provides a detailed description of the temporal and spatial expression of Mef2c in the cerebellum and reveals the postnatal onset and specific expression of Mef2c in Purkinje cells, which are distinct from Mef2a and Mef2d.

Mef 2 family of transcription factors carries out a multitude of functions ranging from neuronal proliferation, differentiation, and survival in various regions of the brain $[4,75]$. In the cerebellum, studies have primarily focused on the function of Mef2 proteins in granule cells, but their role in Purkinje cells is largely unknown. Interference or knockdown of the expression of Mef2a and Mef2d results in reduced survival of cerebellar granule cells [76-80]. Additionally, the expression and transcriptional activity of Mef2a regulates dendritic differentiation of granule cells $[8,81]$ and localization of excitatory synaptic proteins onto granule cell dendrites [82]. In comparison to Mef2a and Mef2d, virtually nothing is known about the function of Mef2c in the cerebellum. The conventional deletion of Mef2a and Mef2c results in embryonic lethality due to cardiovascular defects, precluding analysis of brain development [83, 84]. Brain-specific deletion of Mef2a or $\mathrm{Mef} 2 \mathrm{a} / \mathrm{d}$ did not result in neuronal apoptosis, but the triple deletion of $\mathrm{Mef} 2 \mathrm{a} / \mathrm{c} / \mathrm{d}$ did result in smaller brain size and increased cell death, suggesting redundancy in function of the Mef2 family members in regulation of neuronal survival [5, $11,12]$. Although mouse genetics studies link Mef2 with regulation of neuronal differentiation, survival, and synaptic transmission in the cerebral cortex and hippocampus $[5,11$, 12], consequences of deletion of Mef2 genes on the development of the cerebellum have not yet been examined or reported. Thus, our identification of Mef2c in the regulation of dendrite development of Purkinje cells represents an important first step for a better understanding of the distinct roles of Mef2 transcription factors in the developing cerebellum.

Previous studies in defining the molecular mechanisms responsible for dendritic formation have identified a number of key regulators of calcium-mediated pathways including CDK5, CAMKII, and ERK [85]. All three of these regulators have been demonstrated to directly control the activity of Mef2 transcription factors [48], suggesting that one or more of these regulators could direct Mef2c-mediated dendritic morphogenesis of Purkinje cells. Additionally, Mef2c has 

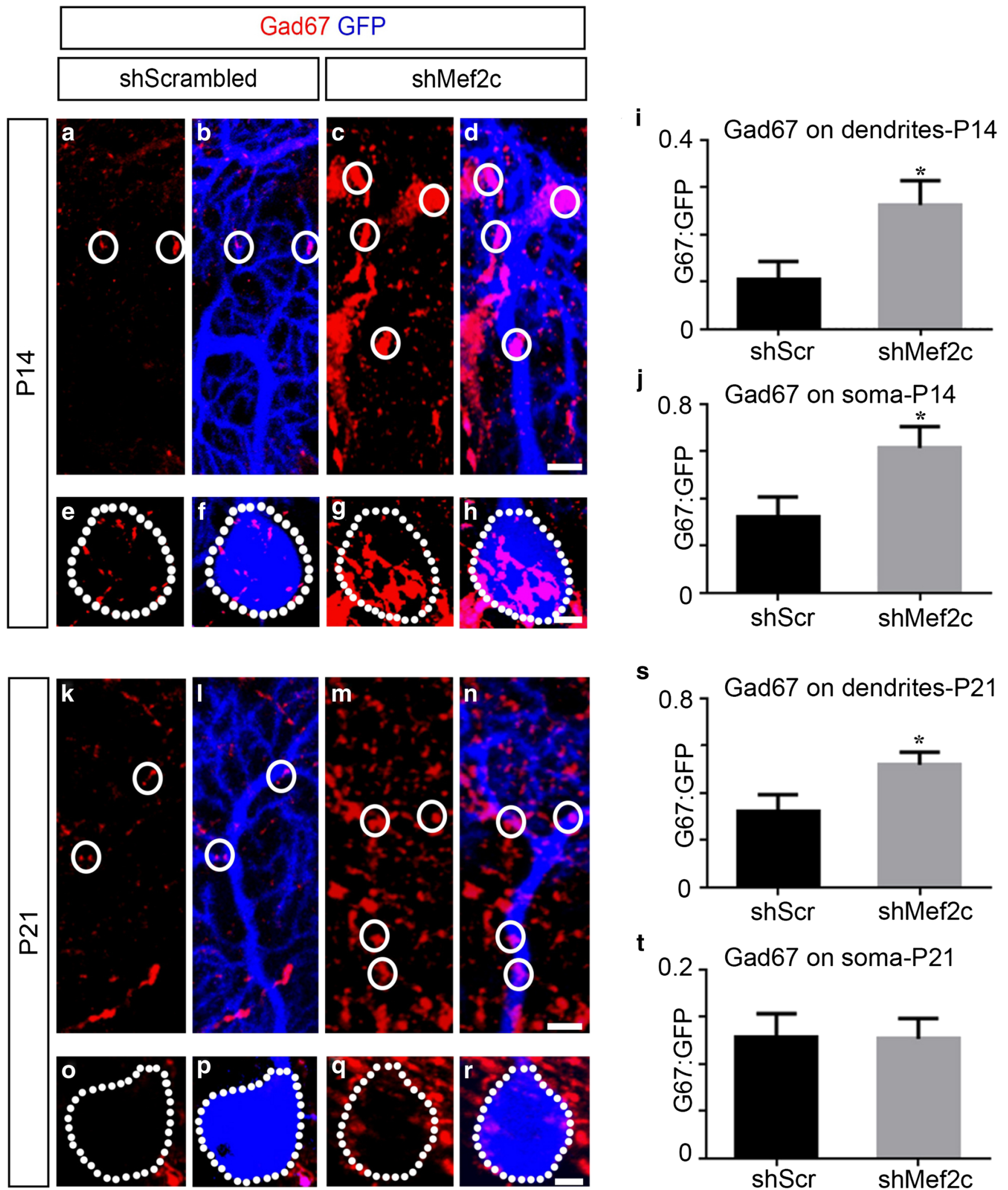

\section{$\mathbf{s}$}
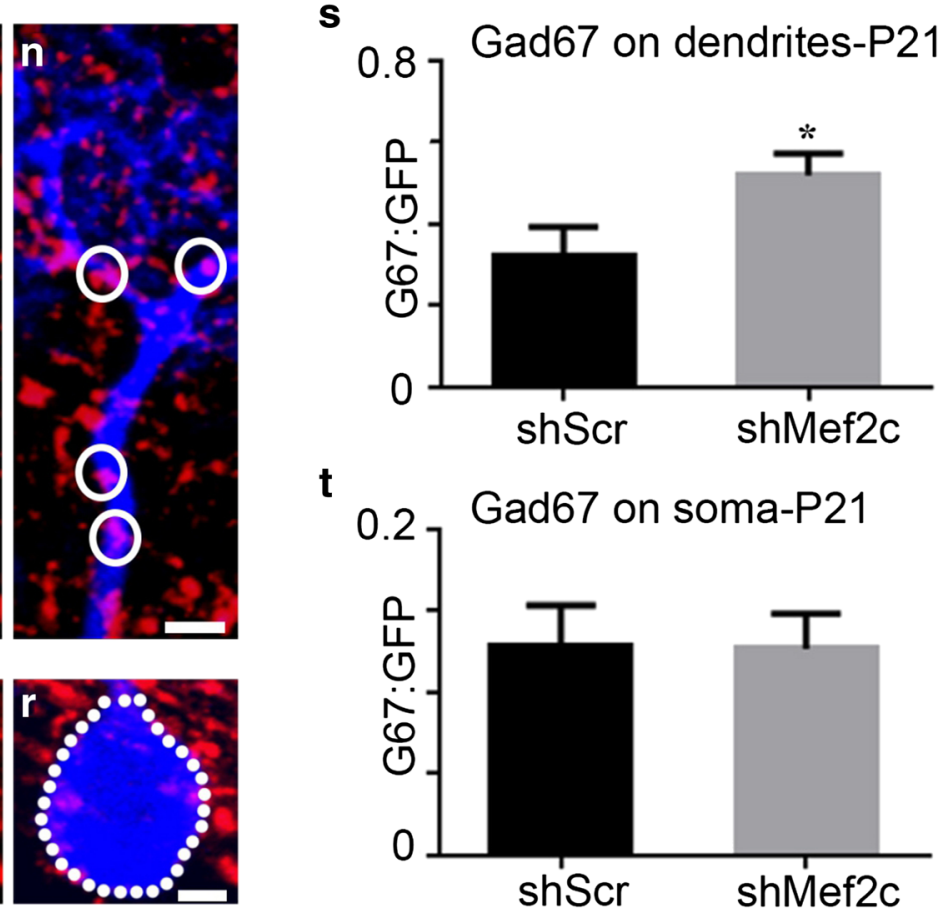

been shown to exert its influence by employing downstream targets such as miRNAs and other translational modulators [86]. The identification and characterization of these molecules and factors with Purkinje cell-specific expression may provide mechanistic insight to how Mef2c controls morphological and synaptic organization of Purkinje cells. Our study provides evidence that Mef2c controls Purkinje cell-mediated functions by regulating the dendritic complexity and, perhaps, 
Fig. 8 Loss of Mef2c results in an increase in Gad67 puncta to the soma and dendrites of Purkinje cells at P14 and only to the dendrites at P21. ah Representative images of Gad67 puncta (red, a, e) on $\mathrm{GFP}^{+}$dendrites (blue, b) and soma (blue, e) of a control Purkinje cell, and Gad67 puncta (red, c, g) on $\mathrm{GFP}^{+}$dendrites (blue, d) and soma (blue, h) of a shMef2c Purkinje cell at P14 after viral transduction at P1. i Analysis of the coincidence of Gad67 puncta on the dendrites of control and shMef2c Purkinje cells expressed as a ratio (shScrambled $0.1044 \pm 0.03779, n=$ 19; shMef2c $0.2619 \pm 0.05124, n=16 ; * P=0.0453 ; N=9$ for shScrambled; 12 for shMef2c). $\mathbf{j}$ Analysis of the coincidence of Gad67 puncta on the soma of control and shMef2c Purkinje cells expressed as a ratio (shScrambled $0.3250 \pm 0.08288, n=18 ; 0.6150 \pm 0.09095, n=16$; $* P=0.0390 ; N=9$ for shScrambled; 12 for shMef2c). k-r Representative images of Gad67 puncta (red, k, o) on $\mathrm{GFP}^{+}$dendrites (blue, I) and soma (blue, p) of a control Purkinje cell, and Gad67 puncta (red, $\mathbf{m}, \mathbf{q}$ ) on $\mathrm{GFP}^{+}$dendrites (blue, $\mathbf{n}$ ) and soma (blue, $\mathbf{r}$ ) of a shMef2c Purkinje cell at P21 after viral transduction at P1. s Analysis of the coincidence of Gad67 puncta on the dendrites of control and shMef2c Purkinje cells expressed as a ratio (shScrambled $0.3238 \pm 0.07044, n=$ 22; shMef2c $0.5184 \pm 0.05366, n=25 ; * P=0.0321 ; N=11$ for shScrambled; 10 for shMef2c). $\mathbf{t}$ Analysis of the coincidence of Gad67 puncta on the soma of control and shMef2c Purkinje cells expressed as a ratio (shScrambled $0.1283 \pm 0.02519, n=21$; shMef2c $0.1267 \pm 0.02175$, $n=25 ; P=0.9603 ; N=11$ for shScrambled; 10 for shMef2c). Gad67, glutamate decarboxylase 67. Data values $=$ mean \pm SEM, Student's $t$ test. Scale bar $=5 \mu \mathrm{m}$

the number of excitatory synaptic inputs. Since disruption of the balance of excitation/inhibition in many regions of the brain has been linked to neurological disorders such as autism, which is associated with the disrupted number and efficacy of Purkinje cells [29], we propose that Mef2c serves as an important genetic entry point to better understand the contribution of Purkinje cells to these disorders.

\section{Mef2c Is a Critical Determinant of Excitatory and Inhibitory Connectivity in the Cerebellum}

Climbing fiber synapses begin to form onto Purkinje cells at P3 and continue until P7 when they are selectively pruned until a single climbing fiber innervates one single Purkinje cell [28]. Although the exact time point of initiation has not been clearly defined, Purkinje cells also receive input from immature parallel fibers and possibly direct but transient mossy fiber input during the first postnatal week [51, 87]. Over the next 2 weeks, climbing fibers compete with parallel fibers to form defined innervation boundaries on each developing Purkinje cell [88]. From our analysis, we observe that by P21, Purkinje cells lacking Mef2c exhibit an increase in parallel fiber innervation and a decrease in climbing fiber innervation. This result raises the possibility that Mef2c may be involved in the process of climbing fiber pruning and/or competition between climbing and parallel fibers during development.

Previous studies have shown that the postnatal loss of Mef2c in hippocampal granule cells resulted in an increase in spine numbers [10], and the conditional deletion of Mef2c in the hippocampal and cortical excitatory neurons leads to a reduction of excitation and a simultaneous increase in inhibition [34]. These studies support a role of Mef2c in modulating the proper balance of excitation and inhibition through regulating spine properties. Purkinje cells receive two major excitatory inputs through parallel and climbing fiber connectivity [89]. During the early postnatal weeks of Purkinje cell development, parallel fibers compete with climbing fibers to define innervation boundaries within the cerebellar cortex and even within each individual Purkinje cell [88]. However, the molecular mechanisms underlying the process of defining climbing fiber-parallel fiber territories are not well understood. Our study revealed that the loss of Mef2c results in a reduction in climbing fiber innervation and concurrent and, perhaps, compensatory increase in both parallel fiber and Gad67 input on dendrites of mature PCs. This is consistent with results by others that a reduction in climbing fiber input onto Purkinje cells resulted in a 2-fold and 4-fold increase in parallel fiber and Gad67 input, respectively [90]. Even though we see changes in the localization of synaptic puncta on Purkinje cells, there remains a possibility that Mef2c directly regulates the expression of vGluT1/2 and Gad67. Thus, Mef2c appears to be an important regulator of the assembly and maintenance of both excitatory and inhibitory inputs to PCs and a key determinant of proper circuit formation and function in the cerebellum.

Acknowledgements We are grateful to Ayumu Konno (Gunma University, Japan) for sharing the L7 minimal promoter and Norliyana Zainolabidin for providing embryonic tissues. We thank Toh Hean Ch'ng and Yasunori Saheki for comments and suggestions on the manuscript.

Funding Information This work was supported by a grant from the Singapore Ministry of Education (RG124/15).

Open Access This article is distributed under the terms of the Creative Commons Attribution 4.0 International License (http:// creativecommons.org/licenses/by/4.0/), which permits unrestricted use, distribution, and reproduction in any medium, provided you give appropriate credit to the original author(s) and the source, provide a link to the Creative Commons license, and indicate if changes were made.

\section{References}

1. Gilissen C, Hehir-Kwa JY, Thung DT, van de Vorst M, van Bon BWM, Willemsen MH, Kwint M, Janssen IM et al (2014) Genome sequencing identifies major causes of severe intellectual disability. Nature 511(7509):344-347

2. Mitchell, A., et al., MEF2C transcription factor is associated with the genetic and epigenetic risk architecture of schizophrenia and improves cognition in mice. Mol Psychiatry, 2017.

3. Parikshak NN, Luo R, Zhang A, Won H, Lowe JK, Chandran V, Horvath S, Geschwind DH (2013) Integrative functional genomic analyses implicate specific molecular pathways and circuits in autism. Cell 155(5):1008-1021

4. Potthoff MJ, Olson EN (2007) MEF2: a central regulator of diverse developmental programs. Development 134(23):4131-4140 
5. Barbosa AC, Kim MS, Ertunc M, Adachi M, Nelson ED, McAnally J, Richardson JA, Kavalali ET et al (2008) MEF2C, a transcription factor that facilitates learning and memory by negative regulation of synapse numbers and function. Proc Natl Acad Sci U S A 105(27):9391-9396

6. Flavell SW, Cowan CW, Kim TK, Greer PL, Lin Y, Paradis S, Griffith EC, Hu LS et al (2006) Activity-dependent regulation of MEF2 transcription factors suppresses excitatory synapse number. Science 311(5763):1008-1012

7. Okamoto S, Krainc D, Sherman K, Lipton SA (2000) Antiapoptotic role of the p38 mitogen-activated protein kinase-myocyte enhancer factor 2 transcription factor pathway during neuronal differentiation. Proc Natl Acad Sci U S A 97(13):7561-7566

8. Shalizi A, Gaudillière B, Yuan Z, Stegmüller J, Shirogane T, Ge Q, Tan Y, Schulman B et al (2006) A calcium-regulated MEF2 sumoylation switch controls postsynaptic differentiation. Science 311(5763):1012-1017

9. Tu S, Akhtar MW, Escorihuela RM, Amador-Arjona A, Swarup V, Parker J, Zaremba JD, Holland T et al (2017) NitroSynapsin therapy for a mouse MEF2C haploinsufficiency model of human autism. Nat Commun 8(1):1488

10. Adachi M, Lin PY, Pranav H, Monteggia LM (2016) Postnatal loss of Mef2c results in dissociation of effects on synapse number and learning and memory. Biol Psychiatry 80(2):140-148

11. Akhtar MW, Kim MS, Adachi M, Morris MJ, Qi X, Richardson JA, Bassel-Duby R, Olson EN et al (2012) In vivo analysis of MEF2 transcription factors in synapse regulation and neuronal survival. PLoS One 7(4):e34863

12. Li H, Radford JC, Ragusa MJ, Shea KL, McKercher SR, Zaremba JD, Soussou W, Nie Z et al (2008) Transcription factor MEF2C influences neural stem/progenitor cell differentiation and maturation in vivo. Proc Natl Acad Sci U S A 105(27):9397-9402

13. Leifer D, Golden J, Kowall NW (1994) Myocyte-specific enhancer binding factor $2 \mathrm{C}$ expression in human brain development. Neuroscience 63(4):1067-1079

14. Leifer D, Krainc D, Yu YT, McDermott J, Breitbart RE, Heng J, Neve RL, Kosofsky B et al (1993) MEF2C, a MADS/MEF2-family transcription factor expressed in a laminar distribution in cerebral cortex. Proc Natl Acad Sci U S A 90(4):1546-1550

15. Leifer D, Li YL, Wehr K (1997) Myocyte-specific enhancer binding factor $2 \mathrm{C}$ expression in fetal mouse brain development. $\mathrm{J}$ Mol Neurosci 8(2):131-143

16. Flavell SW, Kim TK, Gray JM, Harmin DA, Hemberg M, Hong EJ, Markenscoff-Papadimitriou E, Bear DM et al (2008) Genome-wide analysis of MEF2 transcriptional program reveals synaptic target genes and neuronal activity-dependent polyadenylation site selection. Neuron 60(6):1022-1038

17. Reeber SL, Otis TS, Sillitoe RV (2013) New roles for the cerebellum in health and disease. Front Syst Neurosci 7:83

18. Schmahmann JD (2010) The role of the cerebellum in cognition and emotion: personal reflections since 1982 on the dysmetria of thought hypothesis, and its historical evolution from theory to therapy. Neuropsychol Rev 20(3):236-260

19. Wang SS, Kloth AD, Badura A (2014) The cerebellum, sensitive periods, and autism. Neuron 83(3):518-532

20. Rogers TD et al (2013) Is autism a disease of the cerebellum? An integration of clinical and pre-clinical research. Front Syst Neurosci $7: 15$

21. Skefos J, Cummings C, Enzer K, Holiday J, Weed K, Levy E, Yuce T, Kemper T et al (2014) Regional alterations in purkinje cell density in patients with autism. PLoS One 9(2):e81255

22. Sudarov A (2013) Defining the role of cerebellar Purkinje cells in autism spectrum disorders. Cerebellum 12(6):950-955

23. Tsai PT, Hull C, Chu YX, Greene-Colozzi E, Sadowski AR, Leech JM, Steinberg J, Crawley JN et al (2012) Autistic-like behaviour and cerebellar dysfunction in Purkinje cell Tsc1 mutant mice. Nature 488(7413):647-651

24. Eccles, J.C., M. Ito, and J.n. Szentágothai, The cerebellum as a neuronal machine. 1967, Berlin, New York etc.: Springer-Verlag. 335 p.

25. Palay, S.L. and V. Chan-Palay, Cerebellar cortex: cytology and organization. 1974, Berlin, Heidelberg, New York,: Springer. xii, $348 \mathrm{p}$.

26. Altman J, Bayer SA (1978) Prenatal development of the cerebellar system in the rat. II. Cytogenesis and histogenesis of the inferior olive, pontine gray, and the precerebellar reticular nuclei. J Comp Neurol 179(1):49-75

27. Yuasa S, Kawamura K, Ono K, Yamakuni T, Takahashi Y (1991) Development and migration of Purkinje cells in the mouse cerebellar primordium. Anat Embryol 184(3):195-212

28. Sotelo C, Dusart I (2009) Intrinsic versus extrinsic determinants during the development of Purkinje cell dendrites. Neuroscience 162(3):589-600

29. Nelson SB, Valakh V (2015) Excitatory/inhibitory balance and circuit homeostasis in autism spectrum disorders. Neuron 87(4):684 698

30. Yizhar O, Fenno LE, Prigge M, Schneider F, Davidson TJ, O'Shea DJ, Sohal VS, Goshen I et al (2011) Neocortical excitation/ inhibition balance in information processing and social dysfunction. Nature 477(7363): 171-178

31. Vosshall LB, Amrein H, Morozov PS, Rzhetsky A, Axel R (1999) A spatial map of olfactory receptor expression in the Drosophila antenna. Cell 96(5):725-736

32. Sawada Y, Kajiwara G, Iizuka A, Takayama K, Shuvaev AN, Koyama C, Hirai H (2010) High transgene expression by lentiviral vectors causes maldevelopment of Purkinje cells in vivo. Cerebellum 9(3):291-302

33. Adesnik H, Li G, During MJ, Pleasure SJ, Nicoll RA (2008) NMDA receptors inhibit synapse unsilencing during brain development. Proc Natl Acad Sci 105(14):5597-5602

34. Harrington AJ, Raissi A, Rajkovich K, Berto S, Kumar J, Molinaro G, Raduazzo J, Guo Y et al (2016) MEF2C regulates cortical inhibitory and excitatory synapses and behaviors relevant to neurodevelopmental disorders. Elife 5:e20059

35. Longair MH, Baker DA, Armstrong JD (2011) Simple Neurite Tracer: open source software for reconstruction, visualization and analysis of neuronal processes. Bioinformatics 27(17):2453-2454

36. Lyons GE, Micales BK, Schwarz J, Martin JF, Olson EN (1995) Expression of mef2 genes in the mouse central nervous system suggests a role in neuronal maturation. J Neurosci 15(8):5727-5738

37. Esclapez M, Tillakaratne NJ, Kaufman DL, Tobin AJ, Houser CR (1994) Comparative localization of two forms of glutamic acid decarboxylase and their mRNAs in rat brain supports the concept of functional differences between the forms. J Neurosci 14(3 Pt 2): $1834-1855$

38. Celio MR (1990) Calbindin D-28k and parvalbumin in the rat nervous system. Neuroscience 35(2):375-475

39. Hawkes R, Leclerc N (1987) Antigenic map of the rat cerebellar cortex: the distribution of parasagittal bands as revealed by monoclonal anti-Purkinje cell antibody mabQ113. J Comp Neurol 256(1):29-41

40. Neki A, Ohishi H, Kaneko T, Shigemoto R, Nakanishi S, Mizuno N (1996) Pre-and postsynaptic localization of a metabotropic glutamate receptor, mGluR2, in the rat brain: an immunohistochemical study with a monoclonal antibody. Neurosci Lett 202(3):197-200

41. Weyer A, Schilling K (2003) Developmental and cell type-specific expression of the neuronal marker NeuN in the murine cerebellum. J Neurosci Res 73(3):400-409

42. Hori K, Hoshino M (2012) GABAergic neuron specification in the spinal cord, the cerebellum, and the cochlear nucleus. Neural Plasticity 2012:921732 
43. Dusart I, Flamant F (2012) Profound morphological and functional changes of rodent Purkinje cells between the first and the second postnatal weeks: a metamorphosis? Front Neuroanat 6:11

44. Takacs J, Hamori J (1994) Developmental dynamics of Purkinje cells and dendritic spines in rat cerebellar cortex. J Neurosci Res 38(5):515-530

45. Takeo YH, Kakegawa W, Miura E, Yuzaki M (2015) Ror $\alpha$ regulates multiple aspects of dendrite development in cerebellar purkinje cells in vivo. J Neurosci 35(36):12518-12534

46. Sachs AJ, David SA, Haider NB, Nystuen AM (2009) Patterned neuroprotection in the Inpp4a(wbl) mutant mouse cerebellum correlates with the expression of Eaat4. PLoS One 4(12):e8270

47. Mason CA, Christakos S, Catalano SM (1990) Early climbing fiber interactions with Purkinje cells in the postnatal mouse cerebellum. J Comp Neurol 297(1):77-90

48. Kloth AD et al (2015) Cerebellar associative sensory learning defects in five mouse autism models. eLife 4:e6085

49. Martinez-Cerdeno V (2017) Dendrite and spine modifications in autism and related neurodevelopmental disorders in patients and animal models. Developmental Neurobiology 77(4):393-404

50. McKay BE, Turner RW (2005) Physiological and morphological development of the rat cerebellar Purkinje cell. J Physiol 567(3): $829-850$

51. Miyazaki T, Fukaya M, Shimizu H, Watanabe M (2003) Subtype switching of vesicular glutamate transporters at parallel fibrePurkinje cell synapses in developing mouse cerebellum. Eur J Neurosci 17(12):2563-2572

52. Guillemot F (2007) Spatial and temporal specification of neural fates by transcription factor codes. Development 134(21):37713780

53. Polleux F, Ince-Dunn G, Ghosh A (2007) Transcriptional regulation of vertebrate axon guidance and synapse formation. Nat Rev Neurosci 8(5):331-340

54. Santiago C, Bashaw GJ (2014) Transcription factors and effectors that regulate neuronal morphology. Development 141(24):46674680

55. Leslie JH, Nedivi E (2011) Activity-regulated genes as mediators of neural circuit plasticity. Prog Neurobiol 94(3):223-237

56. Loebrich S, Nedivi E (2009) The function of activity-regulated genes in the nervous system. Physiol Rev 89(4):1079-1103

57. West AE, Greenberg ME (2011) Neuronal activity-regulated gene transcription in synapse development and cognitive function. Cold Spring Harb Perspect Biol 3(6)

58. Aruga J, Inoue T, Hoshino J, Mikoshiba K (2002) Zic2 controls cerebellar development in cooperation with Zic1. J Neurosci 22(1): 218-225

59. Ben-Arie N, Bellen HJ, Armstrong DL, McCall AE, Gordadze PR, Guo Q, Matzuk MM, Zoghbi HY (1997) Math1 is essential for genesis of cerebellar granule neurons. Nature 390(6656):169-172

60. Corrales JD, Rocco GL, Blaess S, Guo Q, Joyner AL (2004) Spatial pattern of sonic hedgehog signaling through Gli genes during cerebellum development. Development 131(22):5581-5590

61. Miyata T, Maeda T, Lee JE (1999) NeuroD is required for differentiation of the granule cells in the cerebellum and hippocampus. Genes Dev 13(13):1647-1652

62. Yang XW, Wynder C, Doughty ML, Heintz N (1999) BACmediated gene-dosage analysis reveals a role for Ziprol (Ru49/Zfp38) in progenitor cell proliferation in cerebellum and skin. Nat Genet 22(4):327-335

63. Hoshino M, Nakamura S, Mori K, Kawauchi T, Terao M, Nishimura YV, Fukuda A, Fuse T et al (2005) Ptfla, a bHLH transcriptional gene, defines GABAergic neuronal fates in cerebellum. Neuron 47(2):201-213

64. Yamada M, Seto Y, Taya S, Owa T, Inoue YU, Inoue T, Kawaguchi Y, Nabeshima YI et al (2014) Specification of spatial identities of cerebellar neuron progenitors by ptf1a and atoh1 for proper production of GABAergic and glutamatergic neurons. J Neurosci 34(14):4786-4800

65. Zainolabidin N, Kamath SP, Thanawalla AR, Chen AI (2017) Distinct activities of Tfap2A and Tfap2B in the specification of GABAergic interneurons in the developing cerebellum. Front Mol Neurosci 10:281

66. Minaki Y, Nakatani T, Mizuhara E, Inoue T, Ono Y (2008) Identification of a novel transcriptional corepressor, Corl2, as a cerebellar Purkinje cell-selective marker. Gene Expression Patterns : GEP 8(6):418-423

67. Nakatani T, Minaki Y, Kumai M, Nitta C, Ono Y (2014) The c-Ski family member and transcriptional regulator Corl2/Skor2 promotes early differentiation of cerebellar Purkinje cells. Dev Biol 388(1): 68-80

68. Seto Y, Nakatani T, Masuyama N, Taya S, Kumai M, Minaki Y, Hamaguchi A, Inoue YU et al (2014) Temporal identity transition from Purkinje cell progenitors to GABAergic interneuron progenitors in the cerebellum. Nat Commun 5:3337

69. Zhao Y et al (2007) LIM-homeodomain proteins Lhx1 and Lhx5, and their cofactor Ldb1, control Purkinje cell differentiation in the developing cerebellum. Proc Natl Acad Sci United States Am 104(32):13182-13186

70. Puram SV, Bonni A (2013) Cell-intrinsic drivers of dendrite morphogenesis. Development 140(23):4657-4671

71. Kapfhammer JP (2004) Cellular and molecular control of dendritic growth and development of cerebellar Purkinje cells. Prog Histochem Cytochem 39(3):131-182

72. Boukhtouche F, Doulazmi M, Frederic F, Dusart I, Brugg B, Mariani J (2006) RORalpha, a pivotal nuclear receptor for Purkinje neuron survival and differentiation: from development to ageing. Cerebellum 5(2):97-104

73. Ikeshima $\mathrm{H}$ et al (1995) Expression of a MADS box gene, MEF2D, in neurons of the mouse central nervous system: implication of its binary function in myogenic and neurogenic cell lineages. Neurosci Lett 200(2):117-120

74. Lin X, Shah S, Bulleit RF (1996) The expression of MEF2 genes is implicated in CNS neuronal differentiation. Mol Brain Res 42(2): 307-316

75. Rashid AJ, Cole CJ, Josselyn SA (2014) Emerging roles for MEF2 transcription factors in memory. Genes Brain Behav 13(1):118-125

76. Chan SF, Sances S, Brill LM, Okamoto SI, Zaidi R, McKercher SR, Akhtar MW, Nakanishi N et al (2014) ATM-dependent phosphorylation of MEF2D promotes neuronal survival after DNA damage. J Neurosci 34(13):4640-4653

77. Gaudilliere B, Shi Y, Bonni A (2002) RNA interference reveals a requirement for myocyte enhancer factor $2 \mathrm{~A}$ in activity-dependent neuronal survival. J Biol Chem 277(48):46442-46446

78. Li M, Linseman DA, Allen MP, Meintzer MK, Wang X, Laessig T, Wierman ME, Heidenreich KA (2001) Myocyte enhancer factor 2A and 2D undergo phosphorylation and caspase-mediated degradation during apoptosis of rat cerebellar granule neurons. J Neurosci 21(17):6544-6552

79. Linseman DA et al (2003) Inactivation of the myocyte enhancer factor-2 repressor histone deacetylase- 5 by endogenous $\mathrm{ca}(2+)$ //calmodulin-dependent kinase II promotes depolarizationmediated cerebellar granule neuron survival. J Biol Chem 278(42):41472-41481

80. Mao Z, Bonni A, Xia F, Nadal-Vicens M, Greenberg ME (1999) Neuronal activity-dependent cell survival mediated by transcription factor MEF2. Science 286(5440):785-790

81. Shalizi A, Bilimoria PM, Stegmuller J, Gaudilliere B, Yang Y, Shuai K, Bonni A (2007) PIASx is a MEF2 SUMO E3 ligase that promotes postsynaptic dendritic morphogenesis. J Neurosci 27(37): 10037-10046

82. Yamada T, Yang Y, Huang J, Coppola G, Geschwind DH, Bonni A (2013) Sumoylated MEF2A coordinately eliminates orphan 
presynaptic sites and promotes maturation of presynaptic boutons. J Neurosci 33(11):4726-4740

83. Lin Q, Schwarz J, Bucana C, Olson EN (1997) Control of mouse cardiac morphogenesis and myogenesis by transcription factor MEF2C. Science 276(5317):1404-1407

84. Naya FJ, Black BL, Wu H, Bassel-Duby R, Richardson JA, Hill JA, Olson EN (2002) Mitochondrial deficiency and cardiac sudden death in mice lacking the MEF2A transcription factor. Nat Med 8(11):1303-1309

85. Miller FD, Kaplan DR (2003) Signaling mechanisms underlying dendrite formation. Curr Opin Neurobiol 13(3):391-398

86. Fiore R, Khudayberdiev S, Christensen M, Siegel G, Flavell SW, Kim TK, Greenberg ME, Schratt G (2009) Mef2-mediated transcription of the miR379-410 cluster regulates activity-dependent dendritogenesis by fine-tuning Pumilio2 protein levels. EMBO J 28(6):697-710
87. Takeda T, Maekawa K (1989) Transient direct connection of vestibular mossy fibers to the vestibulocerebellar Purkinje cells in early postnatal development of kittens. Neuroscience 32(1):99-111

88. Ichikawa R, Hashimoto K, Miyazaki T, Uchigashima M, Yamasaki M, Aiba A, Kano M, Watanabe M (2016) Territories of heterologous inputs onto Purkinje cell dendrites are segregated by mGluR1dependent parallel fiber synapse elimination. Proc Natl Acad Sci U S A 113(8):2282-2287

89. Altman, J. and S.A. Bayer, Development of the cerebellar system : in relation to its evolution, structure, and functions. 1997, Boca Raton: CRC Press. 783 p., 16 p. of plates.

90. Drengler SM, Oltmans GA (1993) Rapid increases in cerebellar Purkinje cell glutamic acid decarboxylase (GAD67) mRNA after lesion-induced increases in cell firing. Brain Res 615(1):175-179 